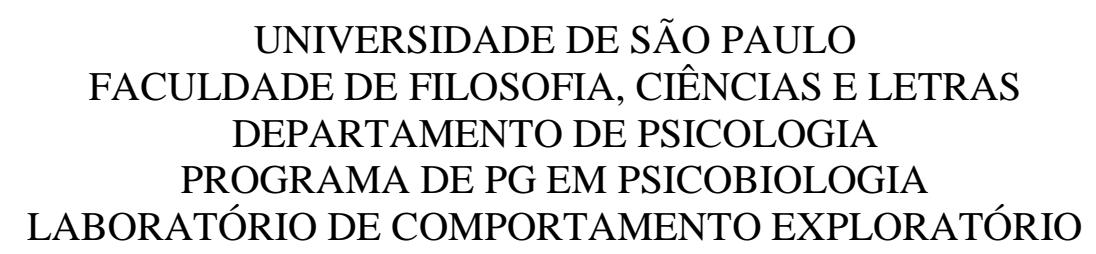

Validação da preferência claro/escuro como modelo comportamental de ansiedade no Carassius auratus (peixe dourado)

Thiago Marques de Brito

Ribeirão Preto - SP

2011 
Thiago Marques de Brito

\section{Validação da preferência claro/escuro como modelo comportamental de ansiedade no Carassius auratus (peixe dourado)}

Dissertação apresentada à Faculdade de Filosofia Ciências e Letras de Ribeirão Preto, da Universidade de São Paulo, como parte das exigências para a obtenção do título de Mestre em Ciências, área de Psicobiologia.

Orientador: Prof. Silvio Morato

Ribeirão Preto - SP 
AUTORIZO A REPRODUÇÃO E DIVULGAÇÃO TOTAL OU PARCIAL DESTE TRABALHO, POR QUALQUER MEIO CONVENCIONAL OU ELETRÔNICO, PARA FINS DE ESTUDO E PESQUISA, DESDE QUE CITADA A FONTE.

\section{FICHA CATALOGRÁFICA}

Brito. Thiaao Maraues

Validação da preferência claro/escuro como modelo comportamental de ansiedade no Carassius auratus (peixe dourado). - Ribeirão Preto, 2011.

45 p.: 10 il. : $30 \mathrm{~cm}$.

Dissertação de Mestrado, apresentada à Faculdade de Filosofia, Ciências e Letras de Ribeirão Preto/USP - Área de concentração: Psicobiologia.

Orientador: Morato, Silvio.

1. Comportamento exploratório. 2. Ansiedade. 3. Preferência claro/escuro. 4. Carassius auratus. 5. Validação de teste comportamental. 


\section{FOLHA DE APROVAÇÃO}

Thiago Marques de Brito

"Validação da preferência claro/escuro como modelo comportamental de ansiedade no Carassius auratus (peixe dourado)".

Dissertação apresentada à Faculdade de Filosofia, Ciências e Letras de Ribeirão Preto da USP, como parte das exigências para a obtenção do título de Mestre em Ciências. Área: Psicobiologia.

Aprovado em: I_-

\section{Banca Examinadora}

Prof (a). Dr (a).

Instituição:

Assinatura:

Prof (a). Dr (a).

Instituição:

Assinatura:

Prof (a). Dr (a).

Instituição:

Assinatura: 
Dedico este trabalho aos meus pais Geny e Isael grandes mestres inspiradores, inseparáveis amigos e conselheiros, figuras indispensáveis a minha vida. 


\section{Agradecimentos}

A Deus, por ter permitido que eu caminhasse até aqui tanto na minha vida pessoal como acadêmica.

Ao meu orientador e amigo Silvio Morato, pela confiança depositada em mim, por todos os ensinamentos compartilhados, pela imensurável contribuição tanto pessoal como acadêmica, pelas parcerias na música, cafés, e, claro, cervejas e pela amizade sincera.

Ao meu eterno mestre e grande amigo Amauri Gouveia Jr., por ter me iniciado na carreira acadêmica, por ter despertado em mim a paixão pela pesquisa, por ter contribuído para que eu estivesse hoje na pós-graduação e laboratório que sempre desejei, pelas sempre bemhumoradas conversas, por muitas vezes ter sido um pai, irmão, ou simplesmente, e não menos importante, um indispensável amigo.

À prof. Rosana Mattioli, por todo auxílio e paciência no acompanhamento da confecção deste trabalho e por suas importantes considerações ao longo dos relatórios por mim apresentados.

À prof. Sandra Calais, por sua contribuição tanto para minha formação enquanto psicólogo, como no auxílio para que eu pudesse dar continuidade a minha carreira acadêmica em Ribeirão Preto.

À prof. Eliane Gonçalves pelas importantes considerações a cerca do modelo utilizado neste estudo.

Ao prof. Katsumasa Hoshino, pelas conversas inspiradoras e importantes reflexões a cerca do comportamento de peixes.

À banca examinadora, pela atenção dispensada na leitura da dissertação.

À Renata Vicentini, por toda ajuda, conselhos e pro-atividade na resolução de problemas.

À todos os funcionários da sessão de pós-graduação, pelo auxílio e disponibilidade em ajudar sempre que necessário.

Aos companheiros do laboratório de Psicobiologia e Psicopatologia da Unesp de Bauru, Rafa, Maldito, Kpta, Claudio, Brunão e Renatinha, pela amizade e auxílio na coleta de dados, sem os quais esse trabalho não seria possível.

Ao grande companheiro e amigo Caio Maximino, pelas discussões sempre pertinentes a cerca do nosso modelo e por todas as experiências compartilhadas no laboratório e fora dele durante a nossa saudosa estada em baurulândia.

Aos amigos do laboratório de Comportamento Exploratório, Javi, Julian e Carol, pelo companheirismo, ajuda e contribuição na minha adaptação a Ribeirão Preto e a USP. 
Às amigas Ju, Carlinha, Jeane e Danila, por toda ajuda com o material fornecido para o estudo da prova de ingresso no programa da psicobiologia, sem os quais não seria possível a minha aprovação.

Aos meus pais, Geny e Isael, a quem também dedico essa dissertação, pelo amor e esforço incondicional a fim de permitir que eu chegasse até aqui. Por sempre terem sido um modelo de honestidade, humildade, esforço pessoal, amizade e companheirismo. Mamãe, Papai, vocês são a força motriz que impulsiona a minha vida. Amo vocês.

Ao meu amor Luciana Kimie Savay da Silva, pela amizade, cumplicidade e amor. Por toda a ajuda, dedicação, incentivo, companheirismo e paciência durante esses nove anos. Por me fazer uma pessoa melhor.

Aos meus amigos/irmãos Sil, Rafa, Ginê e Gorete, por todo carinho, amor, amizade, companheirismo e sinceridade ao longo desses oito anos. Por auxiliar na minha formação pessoal e acadêmica, e por me fazer acreditar que o fato de se compartilhar pai e mãe, não é condição sine qua non para se ter irmãos.

Às queridas, Josi e Paty, por todo o carinho, incentivo, amor e por me fazer acreditar que a primeira sílaba da palavra cunhada, é um mero capricho da língua portuguesa, pois não reflete a verdadeira relação de carinho, respeito, amizade, admiração e amor que tenho por vocês.

Aos amigo Jão, pelo carinho, amizade e companheirismo.

Amo meu amigo/irmão Marcelo, carinhosamente chamado de Gordinho, por todos esses anos de amizade, carinho, sinceridade e cumplicidade, compartilhando os momentos mais importantes e tristes de nossas vidas.

Ao meus avós Olivia, Ana, Inésio, e in memorian Otacílio, Brito e Maria por todas as orações, incentivo, carinho e amor.

À minha sobrinha Duda, pela inspiração, carinho e por sempre tornar o meu final de semana maravilhoso, mesmo que os demais eventos conspirem contra isso.

Ao meu sogro e sogra, Vilson e Helena, por todo carinho e amizade.

Aos meus amigos da Rep.nico, Betão, Paulinho e Rodrigo, pela amizade, carinho, companheirismo. Pelos frangos fritos e assados do Paulinho. Pelas sopas e refogados do Betão. Pelo Strogonoff do Rodrigo, e por todos os momentos de descontração, rizadas, caminhadas e idas ao Geraldo.

Aos meus amigos da psicobiologia, Brunão, Léo, Rui, Hugo, Diegão, Rafa, Fernandinho, Lucas e Dudu, pelos momentos e histórias memoráveis e divertidíssimas do café, bandejão, corredores e congressos.

À Coordenação de Aperfeiçoamento de Pessoal de Nível Superior (CAPES) pelo apoio financeiro. 
Se A é o sucesso, então A é igual a $\mathrm{X}+\mathrm{Y}+\mathrm{Z}$. $\mathrm{O}$ trabalho é $\mathrm{X}$; $\mathrm{Y}$ é o lazer; e $\mathrm{Z}$ é manter a boca fechada.

Albert Einstein 


\section{Conteúdo}

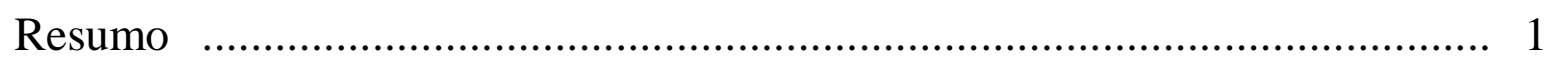

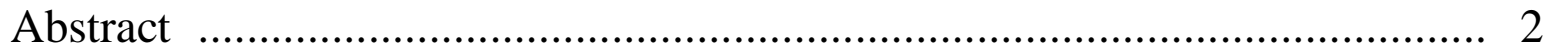

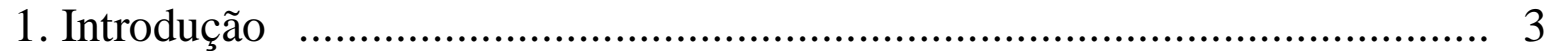

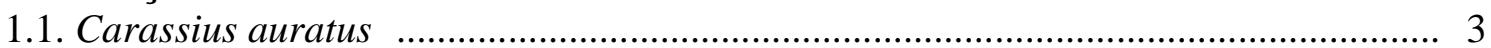

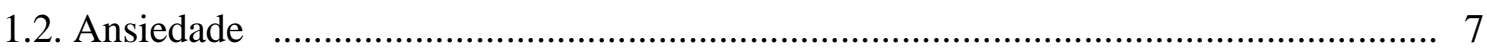

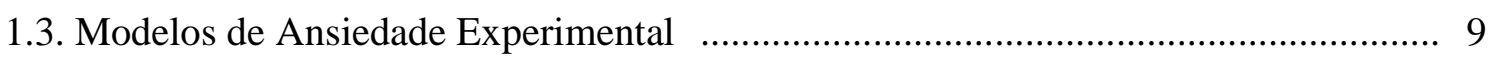

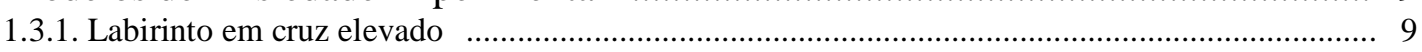

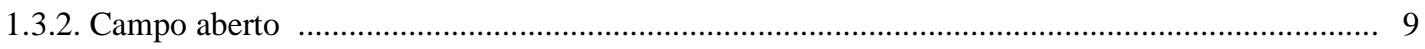

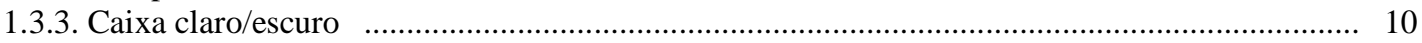

1.3.4. Preferência claro/escuro em peixes …......................................................................... 10

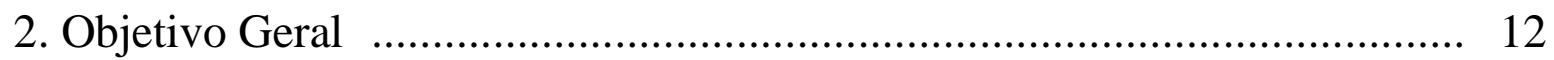

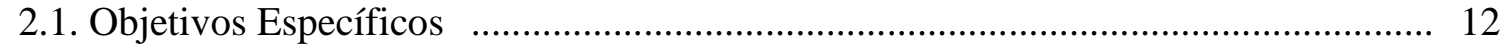

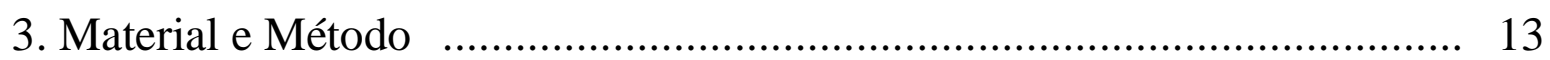

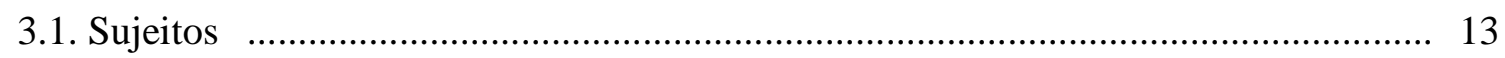

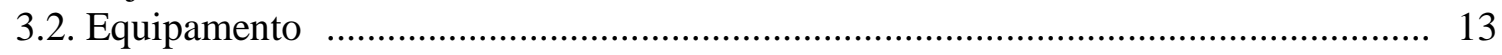

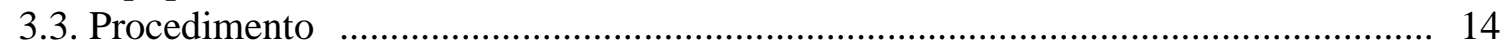

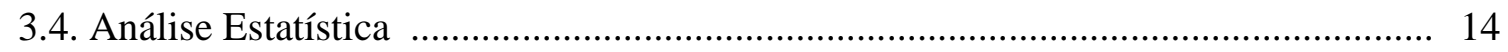

3.4.1. Exposições repetidas ao mesmo aparato .......................................................................... 15

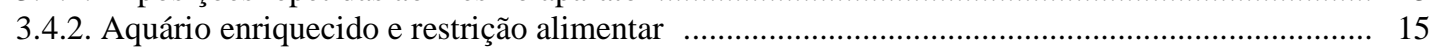

3.4.3. Troca de água, proporções diferentes do compartimento claro e escuro e aquário com metade do comprimento ................................................................................... 15

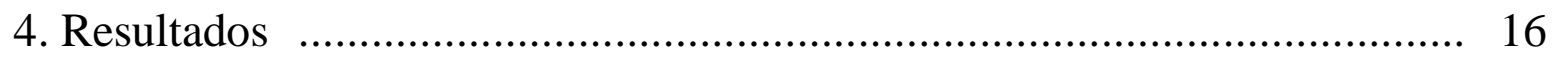

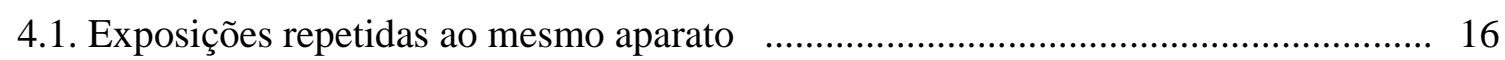

4.2. Aquário enriquecido ...……………………………………………………...... 17

4.3. Restrição Alimentar ...…………………………………………………………... 17

4.4. Troca da água do aquário antes do teste ………………………………….... 18

4.5. Proporções diferentes do compartimento claro $(87,5 \%)$ e escuro $(12,5 \%) \quad$.............. 18

4.6. Proporções diferentes do compartimento claro (75\%) e escuro (25\%) ..................... 20

4.7. Proporções diferentes do compartimento claro (25\%) e escuro (75\%) .................... 20

4.8. Aquário com metade do comprimento ………………………………………….. 22

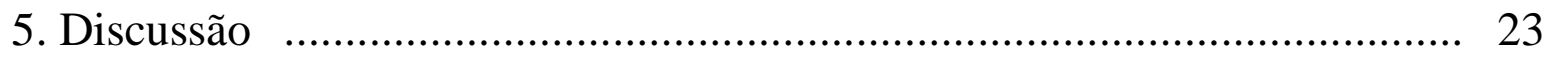

5.1. Exposições repetidas ao mesmo aparato ................................................................ 23

5.2. Aquário enriquecido ...………………………………………………………. 23

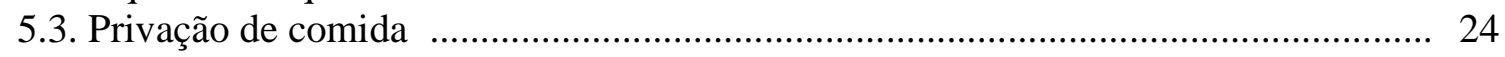

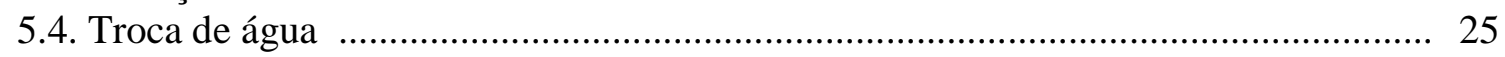

5.5. Proporções difertentes dos compartimentos claro e escuro ........................................ 26

5.6. Aquário com metade do comprimento ………………………………………….... 27

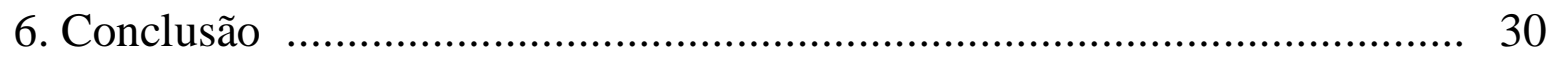

7. Referências Bibliográficas .................................................................... 33 


\section{Resumo}

BRITO, T. M. Validação da preferência claro/escuro como modelo comportamental de ansiedade no peixe Carassius auratus (peixe dourado). 2011. 45f. Dissertação (Mestrado) - Faculdade de Filosofia, Ciências e Letras de Ribeirão Preto, Universidade de São Paulo, Ribeirão Preto, 2011.

A validação de um modelo experimental para se investigar a ansiedade deve estar baseada inicialmente em uma validação comportamental paramétrica, que pressupõe a investigação de respostas relacionadas ao comportamento de defesa da espécie frente às situações aversivas presentes no ambiente de exposição. Assim, o presente trabalho validou a preferência claro/escuro como um modelo comportamental para o estudo da ansiedade no peixe Carassius auratus (peixe dourado). Foram avaliados os seguintes parâmetros: repetição das exposições ao aparato de teste em 5 sessões diárias, privação de comida, aquário enriquecido, troca de água do aquário antes dos testes, proporções diferentes do compartimento claro e escuro, e aquário com a metade do comprimento. Os dados indicaram que as reexposições aumentaram o número de cruzamentos, indicando que a mesma aumenta a exploração do aparato, atenuando os componentes aversivos do ambiente. Os peixes alojados no aquário enriquecido se locomoveram mais no aparato, e não apresentam preferência significativa por nenhum dos compartimentos (claro/escuro), evidenciando que a aversividade do ambiente claro foi atenuada pelo alojamento em um aquário enriquecido. Os animais privados de comida por $48 \mathrm{~h}$ não apresentaram diferenças estatisticamente significativas entre os tempos gastos nos compartimentos claro e escuro do aquário, indicando uma maior exploração do aparato em busca de alimento. Os animais que passaram pelo procedimento de troca de água do aquário de testes não apresentaram preferência por nenhum dos compartimentos, indicando que os peixes, provavelmente, liberam sinalizadores químicos na água que informam seus co-específicos sobre o potencial aversivo do ambiente. Quanto à proporção do aquário, os animais expostos ao aquário teste $75 \%$ claro e $25 \%$ escuro se locomoveram menos que os do aquário controle, indicando que uma maior área clara, pode levar a uma ampliação da aversividade nesse aquário. Quando os sujeitos foram submetidos ao aquário $75 \%$ escuro e $25 \%$ claro $_{2}$ a frequência de cruzamentos foi maior no grupo controle e, nesse caso, a maior locomoção pode estar associada a uma atenuação da aversividade do ambiente relacionada a presença de uma maior área escura. No aquário $87,5 \%$ claro e $12,5 \%$ escuro, os animais do grupo experimental não apresentaram diferenças estatisticamente significativas entre os tempos gastos em nenhum dos compartimentos do aquário, indicando que uma maior área clara (aversiva) altera a preferência por ambientes escuros. Os peixes expostos ao aquário com a metade do comprimento aumentaram sua locomoção, evidenciando que o comprimento do aparato interfere na aversividade do compartimento claro. De forma geral, os dados demonstraram que a manipulação de estímulos ambientais altera os padrões comportamentais exploratórios relacionados à preferência claro/escuro, os quais podem estar associados a diferentes comportamentos relacionados à ansiedade.

Palavras-Chave: Comportamento exploratório, ansiedade, preferência claro/escuro, Carassius auratus, validação de teste comportamental. 


\section{Abstract}

BRITO, T. M. Validation of the light/dark preference as a behavioral model of anxiety in Carassius auratus (goldfish). 2011. 45f. Dissertação (Mestrado) - Faculdade de Filosofia, Ciências e Letras de Ribeirão Preto, Universidade de São Paulo, Ribeirão Preto, 2011.

The validation of an experimental model to investigate the anxiety must be initially based in a parametric behavioral validation, which involves investigating responses related to the defense behavior of the species to cope with aversive situations in the environment of exposure. Thus, the present study validated the light/dark preference as a behavioral model for the study of anxiety in Carassius auratus (goldfish). The following parameters were evaluated: repetition of exposures to the test apparatus in 5 daily sessions, food deprivation, enriched aquarium, exchange of the water of the test aquarium, different proportions of the light and dark compartments, and exposure to an aquarium with half the length of the control one. The data indicated that the repeated exposures increased the number of crossings, indicating that they increased the exploration of the apparatus by reducing the aversive components of the environment. The fish housed in the enriched aquarium displaced more in the test apparatus, showin no significant preference for either the dark or light side, indicating the aversion of the test environment was attenuated by the exposure to the enriched aquarium. 48-H food-deprived animals showed no statistically significant differences between the times spent in either side of the test aquarium, indicating more intense exploration of the test apparatus in search of food. The animals submitted to the procedure of exchanging the water of the test aquarium before testing did not show preference for either side, indicating that the fish probably release chemical signals in the water which inform their conspecifics of the potential aversiveness of environment. As to the proportion of the aquarium, animals exposed to the $75 \%$ light $25 \%$ dark test aquarium displaced less than the ones exposed to the control aquarium, indicating that a larger light area can lead to an increase in the aversiveness of the aquarium. When the subjects were exposed to the $75 \%$ dark $25 \%$ light aquarium, the frequency of crossings was greater for the control group and, in this case, the increased locomotion may be associated with an attenuation in the aversiveness of the environment related to the presence of a larger dark area. In the $87.5 \%$ light $12.5 \%$ dark aquarium, the animals in the experimental group did not present statistically significant differences between the times spent on either the light or dark sides of the apparatus, indicating that a larger light (aversive) area alters the preference for dark environments. The fishes exposed the aquarium with half the length increased their locomotion, indicating that the length of the apparatus interferes with the aversiveness of the light compartment. Overall, the data showed that manipulating environmental stimuli affects exploratory behavior patterns related to light/dark preference, which may be associated with different anxiety-related behaviors.

Keywords: Exploratory behavior, anxiety, light/dark preference, Carassius auratus, behavioral test validation. 


\section{Introdução}

\subsection{Carassius auratus}

De forma geral, os peixes constituem um conjunto de espécies que vivem em ambiente aquático, possuem escamas (mesmo os peixes chamados de couro ou os tubarões as possuem, mas não com características similares), utilizam-se de movimentos da base da cauda para locomoverem-se e têm o sistema olfativo diferenciado do da respiração (Pough; Janis; Heiser, 2003).

O peixe dourado (goldfish; Figura 1) é uma carpa Crucian, da subfamília das carpas, do gênero Carassius (Ciprinídeos, Cyprinidae), que provavelmente se originou de uma mutação da carpa Crucian na China imperial (Komiyama et al., 2009). Peixe facilmente domesticável, pode ser considerado atualmente um dos principais animais de aquarismo no Brasil pois, aliado à domesticação, apresenta pequeno porte (peso máximo de $30 \mathrm{~g}$ ) e se adapta facilmente a diferentes condições ambientais, como temperatura, umidade, pequenas variações de pH (Gouveia Jr; Maximino; Brito., 2006).

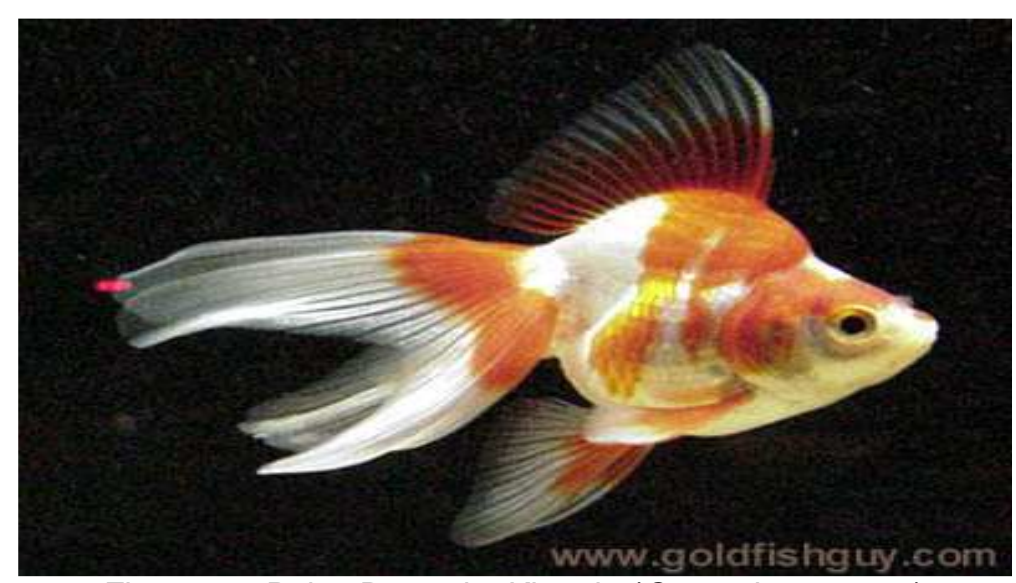

Figura 1 - Peixe Dourado, Kinguio (Carassius auratus)

O peixe dourado, juntamente com a carpa, foram os primeiros vertebrados em que foi possível localizar três tipos diferentes de células visuais do tipo cone. O primeiro apresenta resposta de células ganglionares e bipolares à oponência de cores (amarelo-azul, ou verdevermelho) e oponência dupla de cores (amarelo-azul e verde-vermelho), características estas também observadas em humanos e outras espécies que aparentemente possuem um córtex visual desenvolvido (Neumeyer, et al, 2002). 
Tais aspectos permitiram que o peixe dourado fosse caracterizado como uma das principais espécies utilizadas para se estudar o sistema visual, pois é um animal que possui uma visão tetracromática altamente especializada, facilmente treinado em observações comportamentais e que apresenta uma retina que pode ser investigada com certa tranqüilidade a partir de técnicas eletrofisiológicas (Dor et al, 1997, Neumeyer, et al, 2002). Assim, a especialização do sistema visual dessa espécie, o torna um animal interessante para se explorar padrões comportamentais exploratórios relacionados à discriminação de cores e brilho, como é o caso da preferência claro/escuro.

Thorndike (1911) já realizava experimentos com a espécie Fundulus sp desde o início do século 20. Neles o autor condicionava os animais a se esquivarem de situações aversivas, no caso uma grande intensidade luminosa, pouco tolerada pela espécie, a partir da disponibilização de um esconderijo localizado em uma das regiões do labirinto de teste.

Da mesma forma, o peixe dourado caracteriza-se como uma das primeiras espécies utilizadas como modelo em estudos experimentais (Gouveia Jr; Maximino; Brito, 2006). Tais modelos apresentam um universo relativamente grande de características, objetivos e hipóteses, produzindo materiais que se baseiam desde atividade espontânea, nos quais as respostas emitidas não são treinadas e/ou ensinadas (Kleerekoper et al., 1970; Iigo; Tabata, 1996), até estudos que exigem algum tipo de aprendizagem de respondentes (Scobie; Herman, 1972, Brown; Smith; Peters, 1985, Mattioli et al., 1997, Spieler et al. 1999, Santangelo; Morato; Mattioli, 2001).

Kleerekoper et al. (1970) realizaram um estudo descritivo do padrão de locomoção do peixe dourado em um campo aberto. Os mesmos registraram a angulação da mudança de direção dos animais, frequência de viradas, preferência dos animais por virar para a esquerda ou direita, velocidade dos movimentos, entre outros. Os dados gerados pouco contribuem para uma interpretação funcional de alguns comportamentos apresentados pelos peixes no campo aberto, porém, aponta dados importantes a cerca da identificação dos comportamentos relacionados à locomoção para essa espécie.

Iigo e Tabata (1996) realizaram um estudo que investigava a influência do ciclo circadiano sobre a atividade locomotora do peixe dourado. No primeiro experimento, os eles identificaram que a maioria dos peixes apresentava ciclo circadiano, com uma atividade locomotora mais intensa na fase de luz. Já no segundo experimento, no qual eles variaram as condições de luminosidade do ambiente (todo escuro, todo claro, parcialmente escuro e 
parcialmente claro), comparando tais variações com o ciclo circadiano, os autores observaram que houve uma variação da atividade locomotora, relacionada à fase do ciclo circadiano na qual o animal se encontrava, em função das alterações nas condições de luminosidade do ambiente. Tais dados permitiram os autores concluírem que, apesar do peixe dourado apresentar uma atividade locomotora consistente com condições constantes de variação claro/escuro, a ritimicidade circadiana poderia oscilar de acordo com as diferentes condições de luminosidade do ambiente.

Mattioli, et al. (1997) investigaram a influência da substância P sobre os processos de aprendizagem e memória no peixe dourado. Para isso utilizaram um aquário semelhante ao descrito mais tarde por Maximino et al. (2010), treinando os peixes a procurar alimento no ambiente, até que os mesmos fossem capazes de discriminar entre o compartimento com o alimento e o compartimento sem o alimento. Com a discriminação estabelecida, eram então administrados haloperidol ou solução veículo (24 horas. antes do treino) e substância P ou solução veículo (imediatamente após o treino), e 24 horas após a administração das drogas, registrava-se o tempo gasto para encontrar o alimento. A partir dos resultados, as autoras concluíram que a substância $\mathrm{P}$ poderia promover a melhoria da memória no peixe dourado e que esse efeito poderia estar associado a mecanismos de mediação dopaminérgica nas tarefas de discriminação aprendida.

Santangelo, Morato e Mattioli (2001), utilizando a aquário claro/escuro (Serra et al., 1999), descreveram os efeitos da substância P sobre a tarefa de esquiva do compartimento claro do aquário (naturalmente aversivo para essa espécie). Para isso, colocavam os peixes no compartimento claro e registravam a latência do nado para o compartimento escuro (treino). Após o treino, era então administrada a substância $\mathrm{P}$ ou solução veículo, e 24 horas após o treino, o teste de esquiva era repetido registrando-se novamente a latência do nado para o compartimento escuro. A partir dos resultados, os autores concluíram que a substância P, auxiliava na tarefa de esquiva ao compartimento claro, diminuindo a latência do nado para o compartimento escuro.

Estudos mais recentes, como os de Yoshida, Okamura e Uematsu (2004), Rodriguez et al. (2005) e Yoshida e Hirano (2010), relataram o papel do cerebelo da mediação de processos relacionados à aprendizagem emocional. Yoshida, Okamura e Uematsu (2004) descreveram os efeitos da ablação total e congelamento localizado do corpo cerebelar sobre o medo condicionado medidos a partir da frequência cardíaca no peixe dourado. Para isso, os autores 
fizeram o pareamento de uma luz vermelha (estímulo condicionado) com a apresentação de um estímulo elétrico (estímulo incondicionado) e registraram a frequência de cardíaca (treino). No dia do teste, somente era apresentado o estímulo condicionado, e registrada a resposta cardíaca nos animais. Para os animais que passaram pelo procedimento de ablação total do corpo cerebelar, o procedimento de condicionamento era feito após três dias da data da cirurgia. Já para os peixes que passaram pelo procedimento de congelamento localizado, o condicionamento era iniciado logo após o procedimento cirúrgico. Os resultados permitiram aos autores concluírem que ambos os procedimentos impediram a aquisição da resposta condicionada representada pela bradicardia, o que sugeriria que o corpo cerebelar estaria envolvido na aprendizagem emocional.

Rodríguez et al. (2005), também relataram os efeitos de lesões cerebelares sobre o condicionamento de resposta emocionais e motoras, além de uma tarefa de cognição espacial. Para a investigação dos efeitos sobre o condicionamento de respostas emocionais e motoras, um procedimento semelhante ao descrito por Yoshida, Okamura e Uematsu (2004), foi adotado. Para as respostas relacionadas à tarefa de cognição espacial, foi utilizado um aparato semelhante à tábua-de-buracos para roedores, no qual os peixes deveriam localizar qual o "buraco" que continha alimento. Os dados obtidos permitiram aos autores concluírem que lesões do corpo cerebelar do peixe dourado prejudicam o condicionamento da resposta cardíaca e promovem uma deficiência grave na cognição espacial, porém não interferem nas tarefas locomotoras testadas. Assim, ou autores sugeriram que as funções cognitivas e emocionais do cerebelo poderiam ter evoluído no início da evolução dos vertebrados, sendo preservada ao longo da história filogenética dos grupos de vertebrados existentes.

Yoshida e Hirano (2010) relataram os efeitos da administração de microinjeção de Lindocaína no corpo cerebelar do peixe dourado sobre o condicionamento clássico de medo. Utilizando-se de um procedimento semelhante ao descrito por Yoshida, Okamura e Uematsu (2004), os autores concluíram, a partir dos dados obtidos, que a lidocaína prejudicou a aquisição de bradicardia condicionado, assim como no estudo anterior desse grupo de pesquisadores, reforçando a ideia de que o corpo cerebelar estaria envolvido na aprendizagem emocional.

Os dados gerados a partir destes estudos nos permitem afirmar que atualmente possuímos uma compreensão maior acerca das bases etológicas e fisiológicas relacionadas ao comportamento exploratório e de defesa do peixe dourado. Tais fatores se mostram 
importantes na medida em que auxiliam no fornecimento de informações essenciais a investigações experimentais de outra natureza, como por exemplo, da utilização do peixe dourado como um possível modelo para se estudar reações de defesa do tipo da ansiedade.

\subsection{Ansiedade}

A ansiedade, segundo Brandão (2004), pode ser definida como o um estado subjetivo de apreensão ou tensão, difuso ou vago, sendo na maioria das vezes acompanhado por uma ou mais sensações físicas (aumento da pressão arterial, frequiência cardíaca, defecação etc) produzidas a partir de situações que sinalizem perigo em potencial, levando à classe de comportamentos que se expressam diante de respostas de inquietação, como por exemplo, o aumento da locomoção.

A circutaria que medeia este processo do tipo ansiedade está relacionada com a ativação da amídala e sistema septo-hipocampal (Gray, 1982, File 1996, McNaughton; Corr, 2004), que serviriam de interface entre o neocórtex e o sistema límbico subcortical, que por sua vez, receberia projeções do córtex temporal medial (síntese das informações advindas de diferentes sistemas sensoriais).

Segundo (Northcutt, 1981, Portavella et al., 2004, Portavella; Vargas, 2005) tal base fisiológica poderia ser generalizada para todos os vertebrados, não sendo diferente no caso dos peixes, nos quais poderíamos encontrar estruturas homólogas do sistema septo hipocampal e da amídala, respectivamente o pallio lateral e pallio medial (Portavella; Vargas, 2005, Vargas et al., 2009). Porém, ao se falar em estruturas homólogas, principalmente as do sistema nervoso central, todo um cuidado deve ser prestado pois, como salienta (Aboheif et al., 1997), uma homologia estrutural não implica necessariamente uma função similar.

Dessa forma, quando descrevemos os pallia lateral e medial como homólogos de estruturas do septo hipocampal e da amídala, respectivamente, não necessariamente estamos afirmando que os mesmos possuam a mesma função dessas estruturas (encontradas na maioria dos vertebrados terrestres), mas que os pallia, assim como outras estruturas poderiam indicar semelhanças neuroanatômicas entre essas espécies.

Graeff (1994) e Blanchard e Blanchard (1988) propõem uma reação de defesa baseada em três níveis de ameaça (potencial, distal e proximal) e que se relacionam a quatro estratégias comportamentais: imobilização (freezing), fuga, agressão defensiva ou submissão (Blanchard; Blanchard, 1988).Estes níveis estão relacionados com a probabilidade e proximidade de um 
estímulo potencialmente aversivo, sendo que tais estratégias comportamentais possuem um alto nível de plasticidade em sua apresentação, podendo, inclusive, assumir topografias diversas segundo a historia de vida.

A Tabela 1 sumariza os comportamentos, emoções e as áreas de ativação em mamíferos, nos quais esses fenômenos foram mais estudados.

Tabela 1 - Nível de defesa, substrato neural e emoção relacionada (adaptada de Graeff, 1994).

\begin{tabular}{cccl}
\hline Perigo & Comportamentos & Emoção relacionada & \multicolumn{1}{c}{ Sistema nervoso central } \\
\hline Potencial & Avaliação de risco & Ansiedade & $\begin{array}{l}\text { Amígdala, Sistema septo-hipocampal } \\
\text { (SHS) }\end{array}$ \\
Distal & $\begin{array}{c}\text { Congelamento, fuga, } \\
\text { esquiva. }\end{array}$ & Medo & $\begin{array}{l}\text { Matéria cinzenta periaquiductal-dorsal } \\
\text { (PAG), Núcleos medianos da rafe; SHS, } \\
\text { hipotálamo medial }\end{array}$ \\
Proximal & Fuga, luta. & Pânico & PAG \\
\hline
\end{tabular}

Esse grupo de comportamentos está fisiologicamente relacionado a uma base aminérgica, que já era descrita por Gray desde 1982 a partir de seus estudos em neuropsicologia da ansiedade, e que, mais recentemente, são relacionados com a ação da serotonina (Gray; McNaughton, 2000; Graeff, 2002). A serotonina é o principal neurotransmissor das regiões citadas (amídala, sistema septo hipocampal, etc) que, para Graeff (1997), poderia ser considerada como participando de um sistema dual de ativação de todos os comportamentos em função da proximidade do estimulo.

Outro aspecto importante a se salientar junto a esse grupo de comportamentos está correlacionado à estratégia que é planejada frente a um estímulo interpretado como uma "situação perigosa". Ou seja, como o animal se comporta a partir de uma situação que exige uma reação de defesa. Graeff e Brandão (1993) apontam que o sujeito, diante de uma situação identificada como perigosa, poderá evitar o estímulo por uma determinada ação que envolve a ativação de mecanismos motores que, por sua vez, podem remover o estímulo aversivo (caracterizando dessa forma um comportamento de fuga), ou então podem evitar o esse estímulo (comportamento que caracterizaria a esquiva ativa). Esses casos poderiam ser tratados como ansiedade clássica.

No entanto, se determinado estímulo aversivo, não puder ser removido com o auxílio de comportamentos de fuga ou esquiva ativa, o sujeito pode não exibir qualquer comportamento frente àquele determinado estimulo, o que caracterizaria uma estratégia de 
ativação de mecanismos supressores que, por sua vez, agiriam sobre a supressão de respostas punidas (esquiva inibitória) ou, ainda, se esse comportamento não puder ser evitado pela omissão, poder-se-ía falar em termos de um inicio da expressão de sofrimento (desamparo, depressão).

Esta manutenção evolutiva permite que modelos de ansiedade e depressão possam ser consistentemente generalizados entre as espécies, desde que se conheça a estrutura da ecologia comportamental de cada uma delas e sua base bioquímica. Não se afirma, entretanto, que as espécies são iguais entre si, mas que o conhecimento produzido sobre uma espécie pode colaborar para o conhecimento produzido sobre outras, nesses aspectos evolutivamente conservados (Gouveia Jr; Maximino; Brito, 2006).

\subsection{Modelos de Ansiedade Experimental}

\subsubsection{Labirinto em cruz elevado}

Os modelos experimentais para o estudo da ansiedade utilizam roedores como sujeitos experimentais na maioria de trabalhos, sendo o labririnto em cruz elevado um dos principais modelos utilizados (Pellow et al. 1985, Pellow; File, 1986 e Rodgers et al., 1997). Este, muito utilizado por pesquisadores brasileiros (por exemplo, Morato; Brandão, 1996, 1997; Graeff; Brandão, 1993), consiste basicamente de dois braços abertos $(50 \times 10 \mathrm{~cm})$ cruzados perpendicularmente com dois braços opostos de mesma dimensão. Os dois braços opostos são fechados por paredes de madeira de $40 \mathrm{~cm}$ de altura, salvo pela parte central onde os braços se cruzam. O conjunto todo é elevado $50 \mathrm{~cm}$ acima do piso. Esse aparato é considerado um modelo de conflito, no qual motivações contrárias são geradas por condições características da espécie, ou seja, exploração de novos ambientes se contrapõe à aversão a situações potencialmente aversivas representadas pelos braços abertos (Gouveia Jr, 2001).

\subsubsection{Campo Aberto}

O campo aberto, também conhecido popularmente como arena, é um aparato amplamente utilizado no estudo experimental da ansiedade, composto basicamente de uma plataforma quadrada cercada por paredes de. Assim como o labirinto em cruz elevado, também utiliza roedores como seus principais sujeitos experimentais, tendo nos padrões comportamentais de locomoção, mais especificamente, os espaços mais explorados da arena, a medida que define um animal mais ou menos ansioso, no caso, preferência pelos cantos da 
arena (potencialmente mais ansioso) ou preferência pelo centro do aparato (potencialmente menos ansioso) (Kostowski, et al., 1989, Johnston; File, 1991).

\subsubsection{Caixa claro/escuro}

Descrito inicialmente por Crawley e Goodwin (1980), o teste de transição claro/escuro, assim como o labirinto em cruz elevado, se caracteriza como um modelo de conflito, baseado na tendência natural a explorar ambientes novos versus a esquiva de tais ambientes devido à possibilidade potencial da presença de estímulos aversivos nesse ambiente novo.

Modelo animal baseado em comportamentos incondicionados (Chaouloff et al., 1997), ou seja, respostas que não necessitam de aprendizagem (espontaneas, ligadas à etologia do animal), o teste da transição claro/escuro se ancora na aversividade inata de roedores à ambientes excessivamente claros, sendo tal aversividade medida a partir de componentes ansiogênicos expressados em comportamentos como a menor exposição ao compartimento claro da caixa e o menor número de alternâncias entre os compartimentos (Bourin; Hascoet , 2002).

Esse modelo recebeu várias versões desde o original proposto por Crawley e Goodwin em 1980 (Belzung et al., 1987; Costal et al., 1989; Shimada et al. 1995), porém caracteriza-se basicamente por apresentar um compartimento claro, que na maioria das vezes é iluminado com uma intensidade luminosa relativamente alta, além de, em alguns casos, o compartimento claro também ter suas paredes e piso brancos. E também um compartimento escuro, com pouca ou nenhuma luminosidade, sendo na maioria das vezes composto por paredes e piso pretos.

\subsubsection{Preferência Claro/Escuro em peixes}

O aquário que mede a preferência claro/escuro foi inicialmente descrito por Serra, Medalla e Mattioli (1999) como um modelo que indicava a preferência do paulistinha (Danio rerio, zebrafish, em inglês), por ambientes escuros. Tal afirmação se baseava em um tempo maior de exploração do compartimento escuro do aquário e em uma maior latência do nado para o compartimento claro, quando os animais eram colocados no compartimento escuro (preto) e uma menor latência quando colocados no compartimento claro (branco).

Gouveia jr. et al. (2005) observou o mesmo padrão de preferência por ambientes escuros no peixe dourado (Carassius auratus), utilizando como medida a primeira escolha de compartimento, a frequiência de entradas em cada compartimento, e sugerindo, pela primeira 
vez, a medida da preferência claro/escuro como um possível modelo experimental para o estudo da ansiedade em peixes.

Maximino, et al. (2007, 2010abc, 2011), após amplos estudos com diversas espécies de peixes teleóesteos observou que esse padrão de preferência se estendia por todas as espécies estudadas e que a aversividade a ambientes claros e o conflito gerado pela exploração de ambientes novos versus aversividade intrínseca à ambientes desconhecidos, observados em roedores, também se apresentava de forma clara nos peixes, fato esse, que poderia indicar uma possível aplicação do modelo, assim como nos roedores, ao estudo da ansiedade, levando-se em conta as respostas semelhantes observadas quando expostos ao aquário claro/escuro, além de possíveis homologias de estrutura, citadas anteriormente, entre teleósteos e mamíferos.

Diante desse quadro, pode-se observar que existem poucos trabalhos que exploram respostas de conteúdos emocionais em espécies de peixes. Com certeza esse fato pode estar relacionado com o grande número de espécies existentes, por consequiência, um grande número de diferenças a serem levadas em conta e um cuidado devido, ao se falar em generalizações.

Em contra partida, observa-se tanto um aumento do volume de produção científica na área de estudo do comportamento piscino como um interesse maior dos pesquisadores nesse novo modelo, motivados não apenas por um maior controle de variáveis que o mesmo permite, considerando sua natureza menos complexa, como também pela possibilidade de se investigar questões relacionadas às emoções que ainda não foram respondidas com os modelos utilizados atualmente. 


\section{Objetivo Geral}

Realizar um levantamento e análise de parâmetros que possam auxiliar a compreensão dos comportamentos observados na caixa claro/escuro para o Carassius auratus, na busca do fortalecimento do modelo e clareza na operacionalização dos padrões etológics ligados a respostas relacionadas com ansiedade nessa espécie, fornecendo com isso uma base consistente para a exploração do potencial farmacológico do modelo.

\subsection{Objetivos Específicos}

Mais especificamente, o propósito do presente experimento foi o de investigar (a) as respostas comportamentais produzidas pela reexposição dos peixes ao aquário claro/escuro ao longo de cinco dias, (b) os efeitos do alojamento dos animais no aquário enriquecido sobre a preferência claro/escuro, (c) os efeitos de $48 \mathrm{~h}$ de privação de comida sobre a preferência claro/escuro, (d) os efeitos da troca de água do aquário de testes sobre a preferência claro/escuro, (e) os efeitos de diferentes proporções dos compartimentos claro e escuro do aquário sobre a preferência claro/escuro, e (f) os efeitos do tamanho do aquário de testes sobre a preferência claro/escuro, por meio da redução de seu comprimento. 


\section{Material e Método}

\subsection{Sujeitos}

Para a realização do presente trabalho foram utilizados 90 peixes dourados, comprados junto à loja Aquamundi, localizada na cidade de Bauru-SP e distribuídos aleatoriamente em nove grupos de dez sujeitos cada: (1) controle, (2) cinco exposições ao aquário de teste, (3) aquário enriquecido, (4) privado de comida, (5) com troca prévia de água, (6, 7 e 8) compartimento claro com diferentes proporções $(75 \%, 25 \%$ e 12,5\%), e (9) aquário com metade do comprimento.

Os sujeitos foram mantidos em em número de 10 por aquário-viveiro $(35 \mathrm{x} 45 \mathrm{x}$ $50 \mathrm{~cm}$ ), com filtragem constante de água feita por filtros elétricos (Atmam 60 1), controle de temperatura $\left(26 \pm 2^{\circ} \mathrm{C}\right)$ e de ciclo claro/escuro de iluminação ambiental (14/10 horas, inicio às 7:00 h). No aquário-viveiro dos sujeitos do grupo de enriquecimento ambiental foram colocados três pedaços de tijolo de oito furos, cano de PVC cortado em pedaços de 10 a 15 cm, 300 gramas de carvão ativado, 1 quilo de cascalho miúdo e plantas aquáticas. Como os demais, esses peixes também permaneceram nesse ambiente por 20 dias.

Os sujeitos foram alimentados com ração para peixes (Tetra, Brasil) cinco vezes por semana. Os peixes do grupo de privação permaneceram sem serem alimentados nas $48 \mathrm{~h}$ anteriores ao teste. Todos os animais tiveram um período de habituação de vinte dias antes de se iniciarem os procedimentos de coleta de dados.

\subsection{Equipamento}

Utilizou-se um aquário de testes $(45 \times 10 \times 15 \mathrm{~cm})$, como mostrado na Figura 2, com dois compartimentos, um claro (branco) e outro escuro (preto), com uma área central $(5 \mathrm{~cm})$ delimitada por duas portas corrediças, utilizada para habituação ao novo ambiente e início do teste. Nesse aquário foram realizados todos os testes da preferência claro/escuro, exceto aqueles dos peixes estudados em aquários com diferentes proporções ou medidas. Nesse caso, foram empregados quatro outros aquários. Um deles tinha a metade do comprimento do aquário de testes e a mesma largura. Os outros três eram do mesmo tamanho e largura do aquário de testes porém o compartimento claro tinha diferentes proporções em relação ao escuro $(87,5 \%, 75 \%$ e $25 \%)$. 
Todas as sessões foram gravadas por uma câmera Sony (modelo DCR-DVD610), transferidas e armazenadas em um computador para análise posterior dos dados.

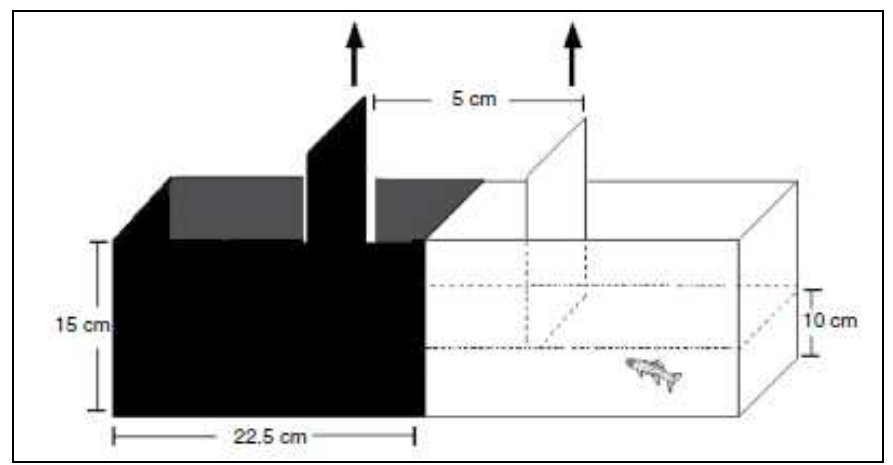

Figura 2 - Aquário de Teste Claro/Escuro

\subsection{Procedimento}

No momento do teste, todos os peixes de um dado aquário-viveiro eram removidos com o uso de uma pequena rede de filó, colocados em um balde (com água mantida em iguais condições à dos aquários) e transportados para a sala de testes. Na hora do teste, cada sujeito era transportado com o uso da rede para o compartimento central do aquário de testes, onde ficava por cinco minutos de habituação. Findo esse período, as duas portas eram suavemente removidas, dando acesso a ambos os compartimentos, permitindo ao animal explorar livremente o ambiente durante um período de quinze minutos. Registrava-se o tempo total gasto em cada compartimento e o número de cruzamentos (transições de um compartimento para outro). Os sujeitos eram testados individualmente e após cada teste o sujeito era removido e transportado para um segundo balde. Quando todos os sujeitos eram testados, o grupo retornava ao aquário-viveiro.

Os sujeitos do grupo controle, de enriquecimento ambiental, de privação de comida e de troca da água do aquário de testes (água proveniente do aquário viveiro) foram expostos uma única vez ao aparato. O grupo de reexposição passou por cinco sessões diárias ao aparato, com intervalo de 24 h entre elas. Os sujeitos do grupo de troca de água eram testados individualmente e, após cada teste, a água do aquário era substituída por outra mantida nas condições do laboratório.

\subsection{Análise Estatística}

A análise estatística foi realizada com auxílio do programa SPSS, versão 13.0. 


\subsubsection{Exposições repetidas ao mesmo aparato}

$\mathrm{Na}$ análise dos dados do grupo de exposições repetidas utilizou-se ANOVA de uma via para medidas repetidas para as variáveis dependentes, aplicada ao tempo total nos compartimentos claro e escuro e à frequência de cruzamento ao longo dos 5 dias. Sempre que apropriado, utilizou-se o teste post-hoc de Student-Newman-Keuls. Além desses, utilizou-se o teste $t$ de Student para medidas pareadas.

\subsubsection{Aquário enriquecido e Privação de Comida}

Utilizou-se o teste $t$ de Student para medidas pareadas e independentes nas variáveis tempo total nos compartimentos claro e escuro e frequiência de cruzamentos.

\subsubsection{Troca de água, proporções diferentes do compartimento claro e escuro e aquário com} metade do comprimento

Utilizou-se o teste $t$ de Student para medidas pareadas e independentes aplicado às variáveis tempo total nos compartimentos claro e escuro e freqüência de cruzamentos. 


\section{Resultados}

\subsection{Exposições repetidas ao mesmo aparato}

A Tabela 2 apresenta a comparação dos tempos totais e latências de exploração dos compartimentos claro e escuro, ao longo das cinco exposições. A ANOVA não indicou diferenças devidas às exposições, tanto para o tempo total no compartimento escuro $\left(\mathrm{F}_{[1,9]}=\right.$ $0,037, \mathrm{P}=0,851)$, como para o tempo no compartimento claro $\left(\mathrm{F}_{[1,9]}=0,003, \mathrm{P}=0,959\right)$. $\mathrm{O}$ teste $t$ de Student para medidas pareadas indicou que a preferência pelo compartimento escuro não se altera ao longo dos dias se compararmos o $1^{\circ}$ dia $\left(t_{[9]}=3,114, \mathrm{P}=0,012\right)$ e o $5^{\circ}$ dia $\left(t_{[9]}\right.$ $=7,831, \mathrm{P}=0,000)$.

Tabela 2. Médias ( \pm Erro Padrão da Média) e valores estatísticos dos tempos totais (claro/escuro), latências de exploração (claro/escuro) e freqüência de cruzamentos.

\begin{tabular}{lcccccccc}
\hline & \multicolumn{9}{c}{ Dias } & & \multicolumn{2}{c}{ Estatística } \\
\cline { 2 - 4 } \multicolumn{1}{c}{ Medidas } & 1 & 2 & 3 & 4 & 5 & & F[1,9] & P \\
\hline Tempo Total Escuro & $693,8 \pm 78,7$ & $623,9 \pm 82,9$ & $551,6 \pm 88,9$ & $692,1 \pm 48,2$ & $642,8 \pm 22,2$ & & 0,037 & 0,851 \\
Tempo Total Claro & $203,7 \pm 78,7$ & $273,7 \pm 82,9$ & $344,8 \pm 89,2$ & $203,9 \pm 47,7$ & $243,3 \pm 29,2$ & & 0,030 & 0,959 \\
\hline
\end{tabular}

A Figura 3 apresenta a comparação entre as frequiências de cruzamentos ao longo dos 5 dias de exposição. A ANOVA indicou efeitos gerais na frequiência de cruzamentos $\left(\mathrm{F}_{[1,9]}=\right.$ $17,763, \mathrm{P}=0,002$ ), sendo que o post hoc revelou que no $5^{\circ}$ dia os animais cruzam mais que no $1^{\circ}$ dia.

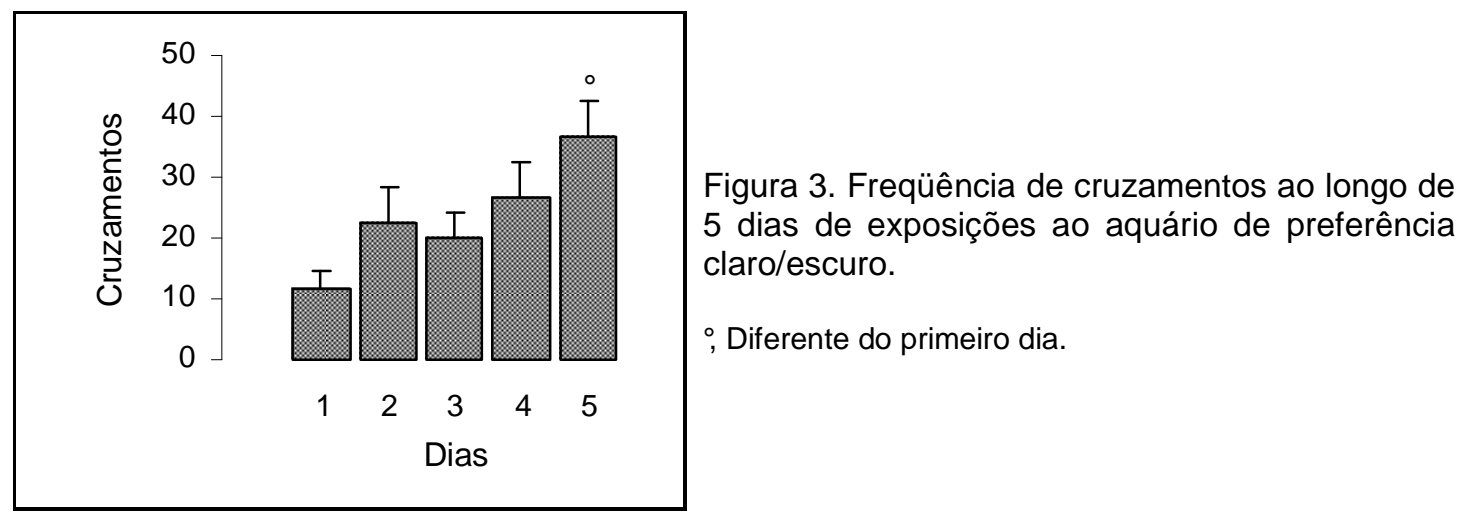




\subsection{Aquário enriquecido}

A Figura 4 apresenta a comparação dos tempos totais gastos nos compartimentos claro e escuro e das freqüências de cruzamentos dos peixes mantidos em aquários simples (controle) e enriquecidos. O teste $t$ de Student para medidas independentes, não indicou diferenças significativas entre os peixes mantidos nos dois tipos de aquário quanto ao tempo gasto nos compartimentos escuro $\left(t_{[18]}=1,962, \mathrm{P}=0,063\right)$ e claro $\left(t_{[18]}=-1,991, \mathrm{P}=0,062\right)$. Já para a comparação entre os cruzamentos dos animais alojados em um aquário simples com os mantidos no aquário enriquecido, o teste mostrou uma média de cruzamentos maior para os animais alojados no enriquecido $\left(t_{[18]}=-2,728, \mathrm{P}=0,014\right)$. O teste $t$ de Student para medidas pareadas indicou que os peixes alojados no aquário simples (controle) passaram mais tempo no compartimento escuro $\left(t_{[9]}=3,114, \mathrm{P}=0,012\right)$ enquanto os animais alojados no aquário enriquecido não apresentaram diferenças estatisticamente significativas $\left(t_{[9]}=0,660, \mathrm{P}=0,526\right)$.

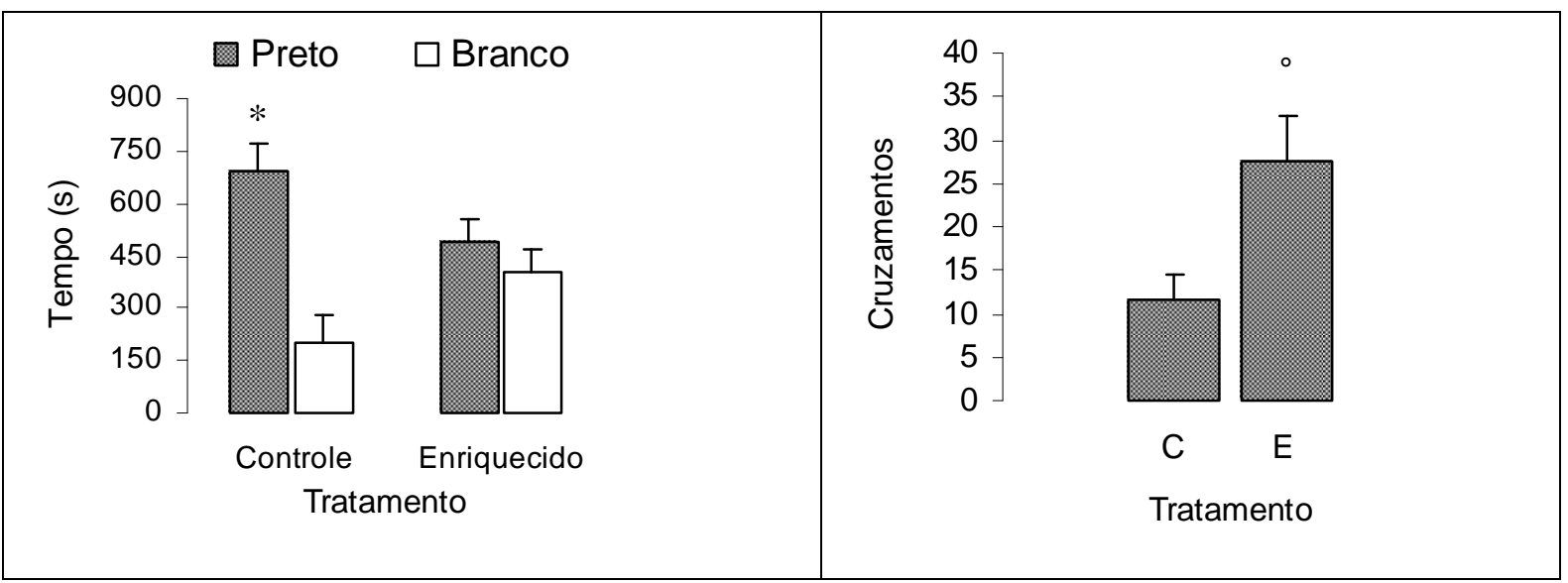

Figura 4. Tempo total nos compartimentos claro/escuro e freqüência de cruzamentos para animais alojados em aquários simples (controle) e enriquecido.

*, Diferente do compartimento branco; ; Diferente do Controle.

\subsection{Restrição Alimentar}

A Figura 5 apresenta a comparação dos tempos totais nos compartimentos claro e escuro, e a freqüência de cruzamentos dos animais sem restrição (controles) e com restrição de alimentos por $48 \mathrm{~h}$. O teste $t$ de Student para medidas independentes, não indicou diferenças significativas entre os tempos gastos nos compartimentos escuro $\left(t_{[18]}=1,399, \mathrm{P}=0,179\right) \mathrm{e}$ claro $\left(t_{[18]}=-1,400 \mathrm{P}=0,178\right)$, nem entre as freqüências de cruzamentos $\left(t_{[18]}=-0,674, \mathrm{P}=\right.$ 0,509). O teste $t$ de Student para medidas pareadas indicou que os peixes sem restrição 
alimentar (controle) passaram mais tempo no compartimento escuro $\left(t_{[9]}=3,114, \mathrm{P}=0,012\right)$. Os animais com restrição alimentar não apresentaram diferenças estatisticamente significativas entre os tempos gastos nos dois compartimentos (claro/escuro) do aquário $\left(t_{[9]}=\right.$ $1,024, \mathrm{P}=0,332)$.

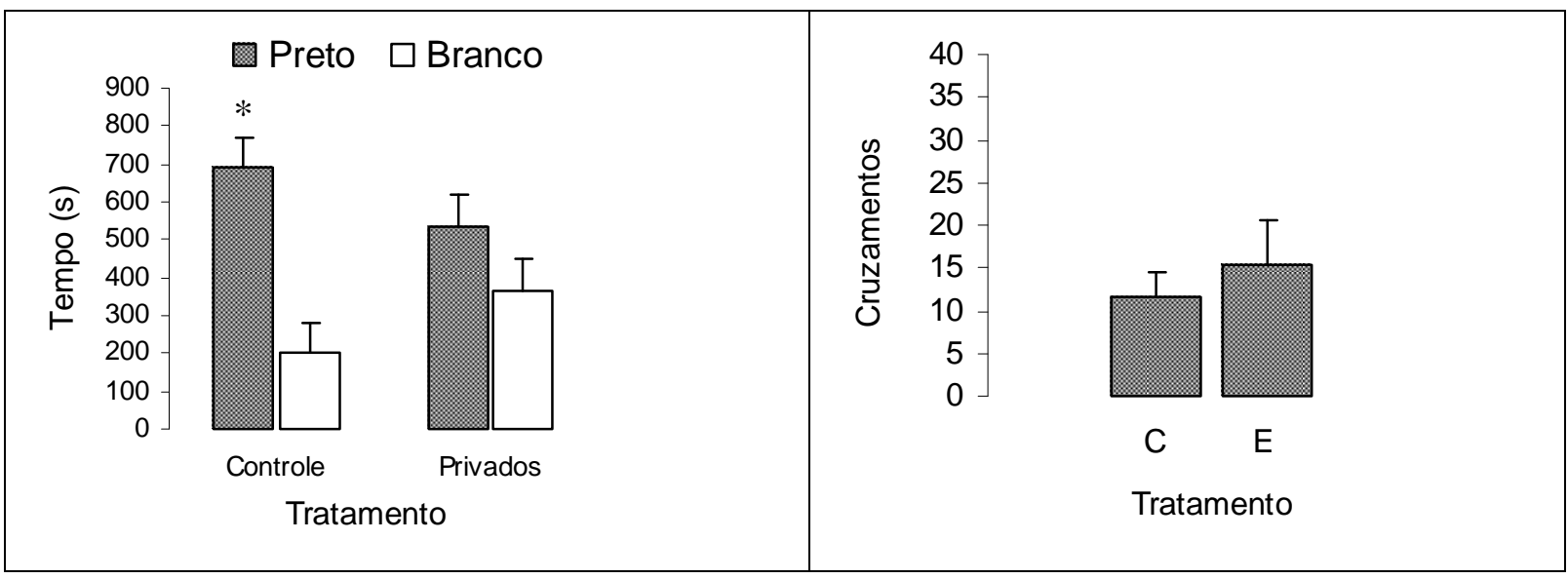

Figura 5. Tempo total nos compartimentos claro/escuro e freqüência de cruzamentos para animais com restrição alimentar (48 horas) e sem restrição alimentar(controle).

* Diferente do compartimento branco

\subsection{Troca da água do aquário antes do teste}

A Figura 6 apresenta a comparação dos tempos totais nos compartimentos claro e escuro, e a frequência de cruzamentos dos animais controles e animais que passaram pelo procedimento de troca de água do aquário de testes (água proveniente do aquário viveiro). $\mathrm{O}$ teste $t$ de Student para medidas independentes, não indicou diferenças significativas entre os tempos gastos nos compartimentos escuro $\left(t_{[18]}=1,720, \mathrm{P}=0,103\right)$ e claro $\left(t_{[18]}=-1,660 \mathrm{P}=\right.$ $0,114)$, assim como entre as frequências de cruzamentos $\left(t_{[18]}=-0,600, \mathrm{P}=0,556\right)$. O teste $t$ de Student para medidas pareadas indicou que os controles passaram mais tempo no compartimento escuro $\left(t_{[9]}=3,114, \mathrm{P}=0,012\right)$. Os animais que passaram pelo procedimento de troca de água do aquário de teste, não apresentaram diferenças estatisticamente significativas entre os tempos gastos nos dois compartimentos (claro/escuro) do aquário $\left(t_{[9]}=\right.$ $0,343, \mathrm{P}=0,739)$. 


\subsection{Proporções diferentes do compartimento claro $(87,5 \%)$ e escuro $(12,5 \%)$}

A Figura 7 apresenta a comparação dos tempos totais nos compartimentos claro e escuro, e a frequência de cruzamentos dos animais que foram expostos ao aquário com

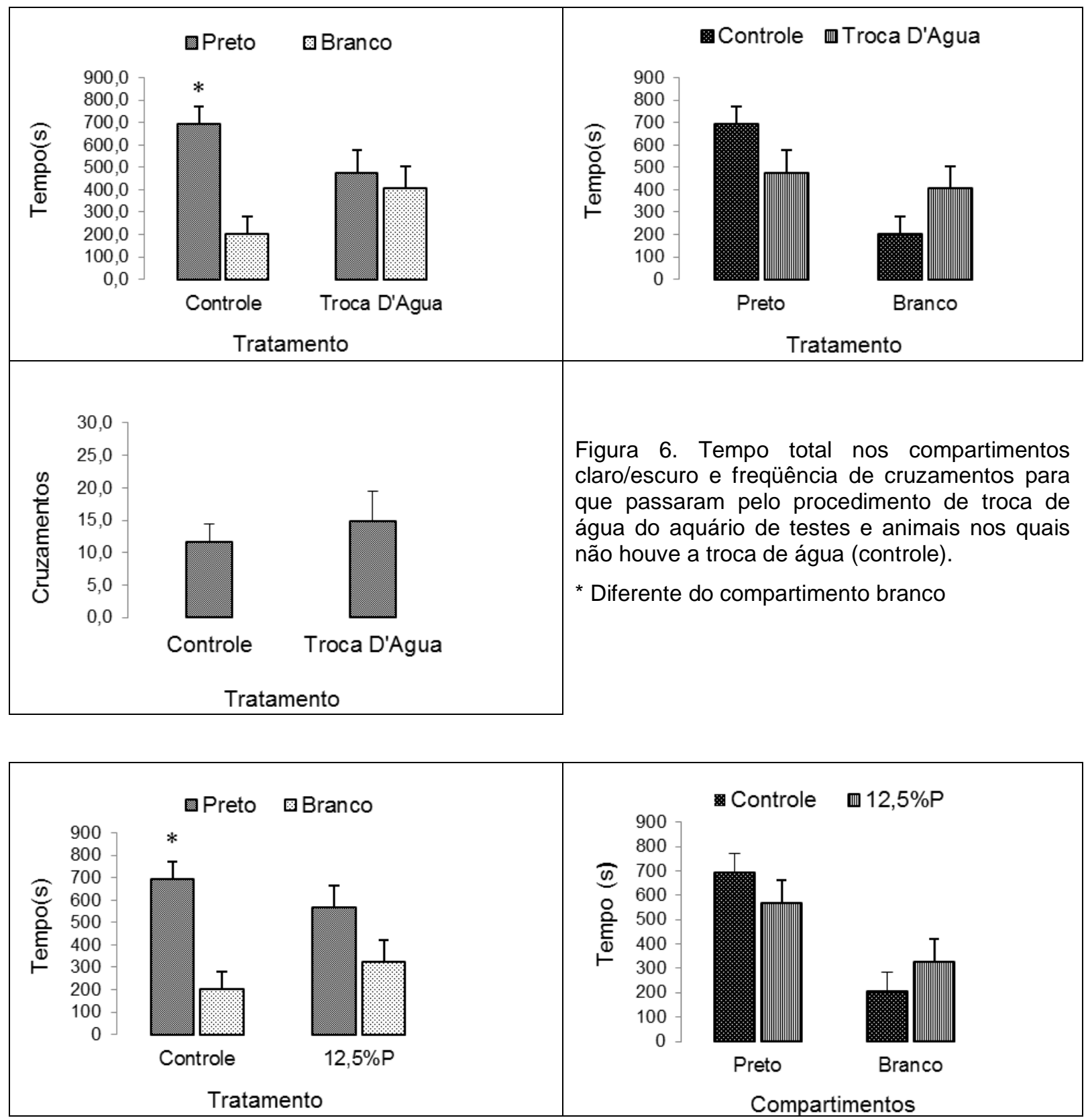




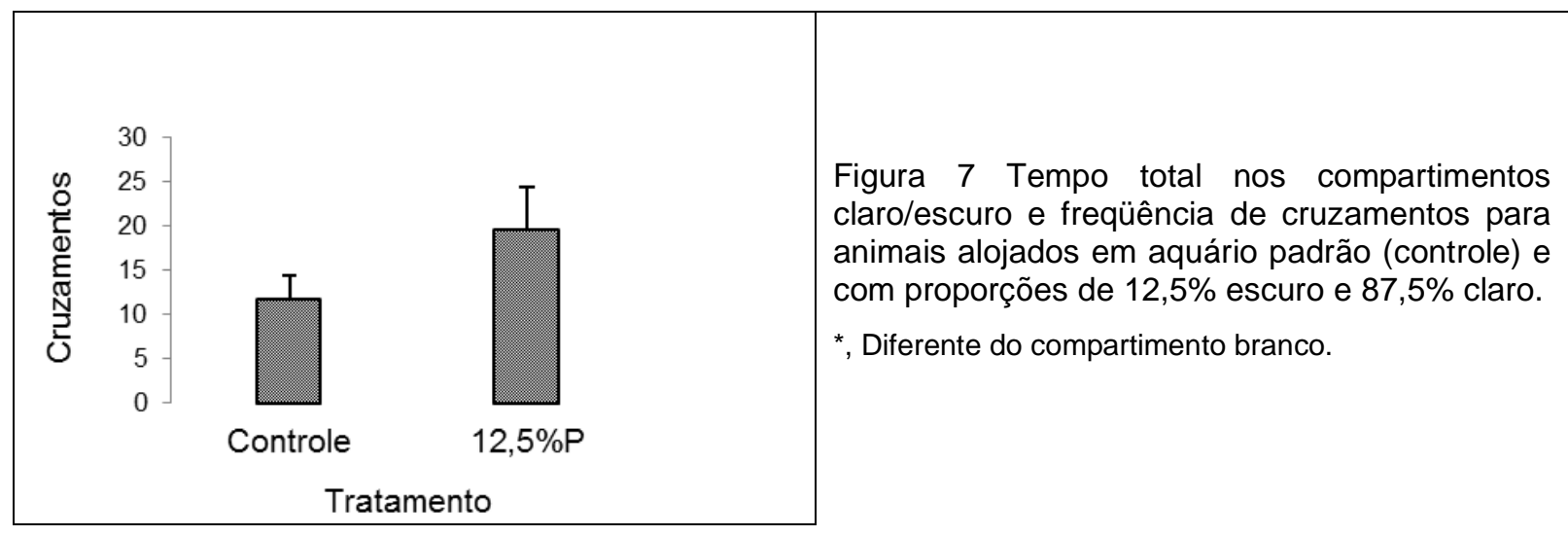

proporções de $12,5 \%$ escuro e $77,5 \%$ claro e animais controles expostos ao aquário padrão ( $50 \%$ claro e $50 \%$ escuro). O teste $t$ de Student para medidas independentes não indicou diferenças entre os tempos gastos nos compartimentos escuro $\left(t_{[18]}=1,016, \mathrm{P}=0,323\right)$ e claro $\left(t_{[18]}=-1,028, \mathrm{P}=0,318\right)$, assim como para a freqüência de cruzamentos $\left(t_{[18]}=-1,478, \mathrm{P}=\right.$ 0,157). O teste $t$ de Student para medidas pareadas indicou que os controles passaram mais tempo no compartimento escuro $\left(t_{[9]}=3,114, \mathrm{P}=0,012\right)$. Os animais que passaram pelo aquário com proporções de $12,5 \%$ escuro e $77,5 \%$ claro não apresentaram diferenças estatisticamente significativas entre os tempos gastos nos dois compartimentos (claro/escuro) do aquário $\left(t_{[9]}=1,330, \mathrm{P}=0,216\right)$.

\subsection{Proporções diferentes do compartimento claro (75\%) e escuro (25\%)}

A Figura 8 apresenta a comparação dos tempos totais nos compartimentos claro e escuro, e a frequência de cruzamentos dos animais que foram expostos ao aquário com proporções de $75 \%$ claro e $25 \%$ escuro e animais expostos ao aquário padrão (50\% claro e $50 \%$ escuro) (controles). O teste $t$ de Student para medidas independentes, não indicou diferenças entre os tempos gastos nos compartimentos escuro $\left(t_{[18]}=-1,289, \mathrm{P}=0,214\right) \mathrm{e}$ claro $\left(t_{[18]}=-1,414, \mathrm{P}=0,114\right)$. Entretanto, a freqüência de cruzamentos é maior no grupo controle $\left(t_{[18]}=3,224, \mathrm{P}=0,05\right)$. O teste $t$ de Student para medidas pareadas indicou que os controles passaram mais tempo no compartimento escuro $\left(t_{[9]}=3,114, \mathrm{P}=0,012\right)$, assim como os animais expostos ao aquário de proporções $75 \%$ claro e $25 \%$ escuro $\left(t_{[9]}=6,437, \mathrm{P}<\right.$ $0,001)$.

\subsection{Proporções diferentes do compartimento claro (25\%) e escuro (75\%)}


A Figura 9 apresenta a comparação dos tempos totais nos compartimentos claro e escuro, e a frequência de cruzamentos dos animais que foram expostos ao aquário com proporções de $75 \%$ escuro e $25 \%$ claro e dos animais controles expostos ao aquário padrão (50\% claro e $50 \%$ escuro). O teste $t$ de Student para medidas independentes não indicou diferenças entre os tempos gastos nos compartimentos escuro $\left(t_{[18]}=0,557, \mathrm{P}=0,585\right)$ e claro $\left(t_{[18]}=1,149, \mathrm{P}=0,265\right)$. Entretanto, a freqüência de cruzamentos é maior no grupo controle $\left(t_{[18]}=2,415, \mathrm{P}=0,027\right)$. O teste $t$ de Student para medidas pareadas indicou que os controles passaram mais tempo no compartimento escuro $\left(t_{[9]}=3,114, \mathrm{P}=0,012\right)$, assim como os animais expostos ao aquário de proporções $75 \%$ claro e $25 \%$ escuro $\left(t_{[9]}=6,437, \mathrm{P}=0,004\right)$.

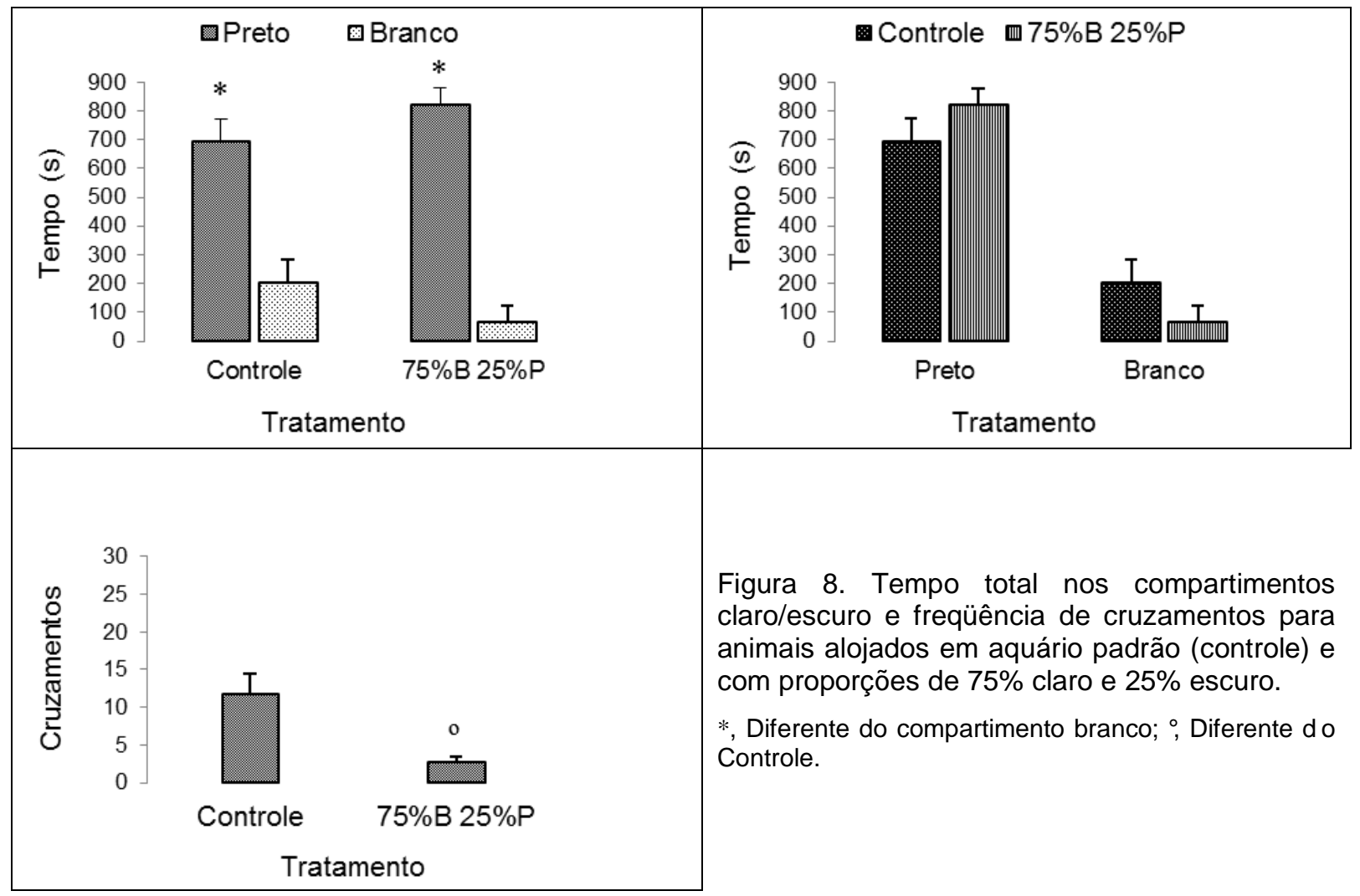




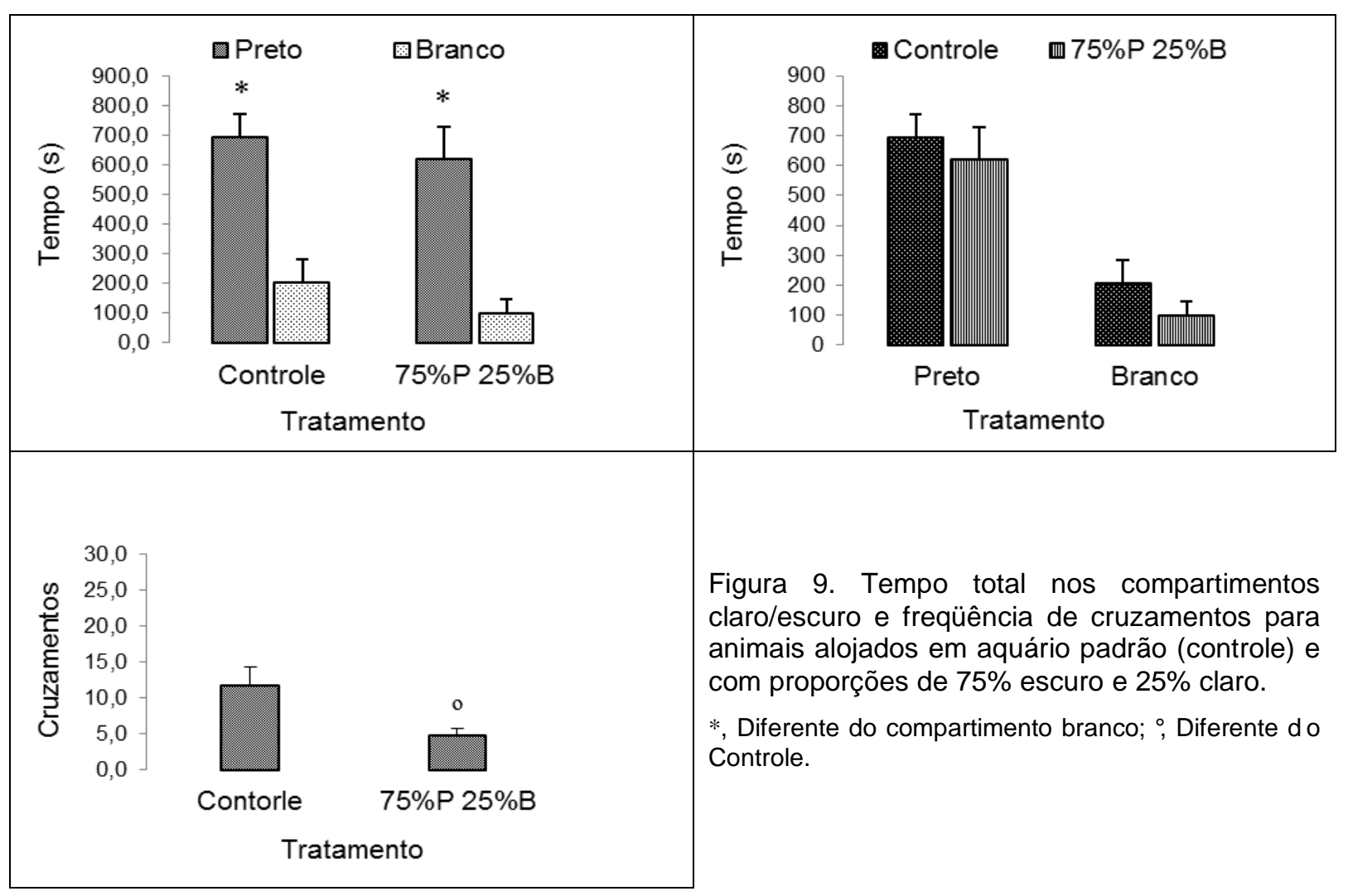

\subsection{Aquário com metade do comprimento}

A Figura 10 apresenta a comparação dos tempos totais nos compartimentos claro e escuro, e a frequência de cruzamentos dos animais que foram expostos ao aquário com a metade do comprimento e animais expostos ao aquário com o comprimento padrão (controles). O teste $t$ de Student para medidas independentes, não indicou diferenças entre os tempos gastos nos compartimentos escuro $\left(t_{[18]}=-0,308, \mathrm{P}=0,762\right)$ e claro $\left(t_{[18]}=0,294, \mathrm{P}=\right.$ 0,772). Entretanto, a freqüência de cruzamentos é maior no grupo exposto ao aquário com a metade do comprimento $\left(t_{[18]}=-2,468, \mathrm{P}=0,024\right)$. O teste $t$ de Student para medidas pareadas indicou que os controles passaram mais tempo no compartimento escuro $\left(t_{[9]}=3,114, \mathrm{P}=\right.$ $0,012)$, assim como os animais expostos ao aquário com a metade do comprimento $\left(t_{[9]}=\right.$ $5,744, \mathrm{P}=0,000)$. 


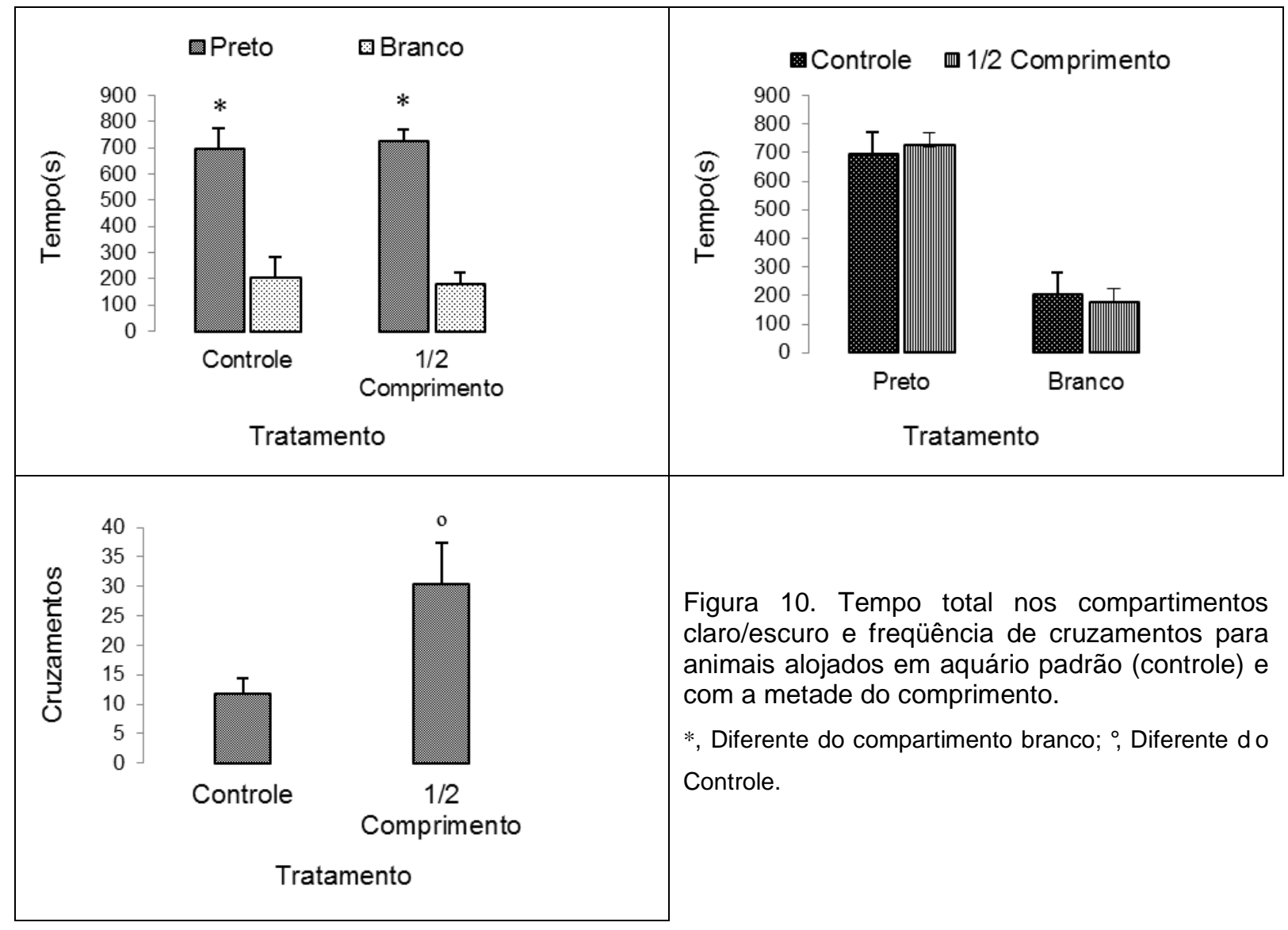




\section{Discussão}

\subsection{Exposições repetidas ao mesmo aparato}

Os resultados apontaram que os cinco dias de exposição à caixa de preferência claro/escuro não alteram o valor aversivo do compartimento claro do aquário, fato esse indicado pelo maior tempo de permanência dos sujeitos no compartimento escuro. Resultados semelhantes também foram observados em trabalhos com roedores (Treit et al., 1992 e Holmes et al., 2001) e com o paulistinha (Maximino, et al., 2010a, 2010b). Porém, o contrário se observa nos trabalhos com o paulistinha, que apresenta uma diminuição no número de cruzamentos ao longo das reexposições, interpretada pelos autores como efeito de habituação ao aparato. No peixe dourado, esse padrão se expressa de forma contrária, apresentando um aumento no número de cruzamentos ao longo dos dias e, por conseguinte, a indicação de uma não habituação ao aparato. Porém, levando-se em consideração que os animais, de uma forma geral, tendem a ampliar seu comportamento exploratório em ambientes que oferecem pouco perigo, poder-se-ia interpretar tal dado como sendo uma atenuação do componente aversivo relacionado ao compartimento claro, como já apontavam Costall et al. (1989), Bourin e Hascoet (2002), em seus estudos com roedores.

\subsection{Aquário enriquecido}

Os resultados demonstraram que o enriquecimento do aquário onde os peixes foram alojados alterou o padrão de exploração do aquário de teste da preferência claro/escuro. Apesar de não se encontrar diferenças na comparação do tempo de permanência em cada um dos compartimentos (claro/escuro) entre os animais mantidos no aquário simples e os mantidos no enriquecido, a análise aponta para o fato de que o padrão comportamental dos animais controle (passam mais tempo no compartimento escuro) não se mantém no caso dos animais alojados no aquário enriquecido. Para esses últimos, não há diferença entre os tempos gastos nos compartimentos claro e escuro. Esse dado pode ser interpretado como resultado da diminuição da aversividade do compartimento claro, provavelmente causada pelas condições de enriquecimento do aquário-viveiro.

Olsson e Dahlborn (2001) propõem que o enriquecimento ambiental em caixas-viveiro de camundongos promove um menor nível de stress nos animais e facilita a expressão de comportamentos semelhantes aos apresentados em ambiente natural. Milshtein, et al. (2004), 
relatam efeitos ansiolíticos do enriquecimento ambiental sobre camundongos expostos ao labirinto em cruz elevado, indicando que os animais alojados em caixas com várias fontes estimuladoras (escada, túneis) permaneciam mais tempo nos braços abertos que os animais controle, fato esse que pode indicar a diminuição de aversividade dos braços abertos para esses animais.

Os resultados do presente trabalho ainda indicaram um maior número de cruzamentos para os peixes mantidos no aquário enriquecido, o que indica um aumento da motivação para explorar o aquário, assim como podemos observar no trabalho de Roy, et al.(2001), no qual os autores também verificaram padrão de exploração semelhante em camundongos expostos aos testes do labirinto em cruz elevado e do campo aberto.

\subsection{Privação de Comida}

De forma geral, a privação de 48 horas de comida parece pouco influenciar a preferência e o padrão de exploração do aquário claro/escuro, apesar de observarmos que, ao contrário do que ocorre no grupo controle (maior tempo no compartimento escuro), os animais privados não apresentam uma tendência clara de escolha pelo compartimento escuro. O que alguns dados da literatura sugerem (Gen, et al., 2003 e Inoue, et al. 2004) é que a privação de comida poderia indicar um perfil ansiolítico, evidenciado pela maior exploração dos braços abertos nos roedores privados de comida. Porém, Gen, et al. (2003), argumentam que talvez esse perfil esteja relacionado à motivação por procurar possíveis alimentos no ambiente, que nessa situação, superaria o fator aversivo presente na exploração dos braços abertos.

Com relação ao perfil ansiolítico, o fato do animal não apresentar uma preferência clara pelo compartimento escuro do aquário, explorando de forma semelhante o compartimento claro, poderia indicar que o componente emocional relacionado à aversividade do compartimento claro estaria atenuado. Porém, essa medida não é clara, e o fato do número de transições nos animais privados não ser significativamente maior que nos animais controle, poderia indicar que o tempo de privação não foi suficiente para o aumento da exploração do aparato em busca de alimento. Tal fato, provavelmente está ligado a uma maior tolerância dos peixes à privação e à escassez de comida. Isso talvez ocorra pela própria seleção do ambiente natural habitado por essas espécies. 


\subsection{Troca de água}

Os resultados indicaram que a troca de água do aquário de teste (água proveniente do aquário viveiro) diminui consideravelmente a preferencia dos peixes pelo ambiente escuro, apesar de se observar que os peixes passam um pouco mais de tempo no compartimento escuro do aparato, essa diferença é muito pequena se comparada aos animais controle. Essa característica, provavelmente, está associada à liberação de substancias químicas (substancia de alarme) na água, o que transfere informações entre os peixes sobre os perigos potenciais oferecidos pelo ambiente no qual estão sendo expostos. Em outras palavras, os dados sugerem que a preferencia pelo ambiente escuro, ou melhor, o componente aversivo associado ao ambiente claro que se pode observar nos animais controle, pode ser atribuído ao acúmulo de informações químicas liberadas pelos co-específicos que estiveram no aparato em exposições anteriores. Esse fato é reforçado pelo padrão exploratório apresentado pelos peixes que passaram pelo procedimento de troca de água, nos quais a ausência de preferencia pelo ambiente escuro está associada, provavelmente, à diminuição de pistas químicas que forneceriam informações acerca dos perigos presentes no ambiente da exposição.

A substancia de alarme parece ser uma importante ferramenta de comunicação entre os organismos aquáticos, relacionada sobretudo com respostas defensivas apresentadas em uma situação de confronto presa-predador e no levantamento de informações acerca de possíveis perigos presentes em um ambiente ocupado por uma determinada espécie (Hall et al. 1995; Handani et al. e Wisenden, 2000; Wisenden e Thiel, 2002 e Speedie e Gerlai, 2008).

Speedie e Gerlai (2008) argumentam que, na presença da substancia de alarme, o paulistinha apresenta um aumento na frequência de movimentos erráticos (nado em ziguezague), associados a situações nas quais os animais são expostos a estímulos dolorosos e/ou situações relacionadas à apresentação de estímulos que provocam respostas de medo. Apresentam, além disso, um aumento importante na coesão do cardume, ou seja, a distância entre os animais do cardume é bem menor quando a substancia de alarme está presente, indicando a preparação para um possível conflito com o predador .

Wisenden e Thiel (2002) afirmam que a substancia de alarme não só serve para indicar a presença de predadores aos co-específicos, como também a presença de presas, aos predadores. Segundo os autores, os predadores naturais de algumas espécies de peixes poderiam, também, identificar essa substancia de alarme, utilizando-se disso para identificar a localização de possíveis presas. Em seu estudo eles verificaram que predadores de alevinos 
aumentaram a frequência de comportamentos de ataque quando na presença de substâncias de alarme produzidas pelos alevinos.

Esses dados, em conjunto com os obtidos no presente estudo, indicam o importante papel da substância de alarme para o comportamento de defesa de peixes e, quando se considera o modelo da preferência claro/escuro, a substancia de alarme pode ter um papel determinante, pois, como foi observado, a ausência dessas pistas químicas, diminuiu de forma importante a aversividade do ambiente claro para o peixe dourado.

\subsection{Proporções diferentes dos compartimentos claro e escuro}

Os resultados encontrados nos aquários com $75 \%$ claro e $25 \%$ escuro e $75 \%$ escuro e $25 \%$ claro foram semelhantes. Os tempos que os animais passaram em ambas as proporções indicaram uma preferência pelo compartimento escuro, assim como os controles, com um pequeno aumento do tempo no compartimento escuro paro os peixes expostos ao aquário de proporção $75 \%$ claro e $25 \%$ escuro, se comparados com os controles.

Os dados evidenciados pela proporção $75 \%$ claro e $25 \%$ escuro já eram esperados, considerando-se que tal distribuição entre as proporções de compartimentos claro e escuro é idêntica à da maioria dos aparatos utilizados no estudo da caixa claro/escuro como um modelo de ansiedade (Crawley e Goodwin, 1980; Crawley et al., 1984, 1997; Hascoet e Bourin, 1998; Hascoet et al., 2000a,b). Pode-se observar também que o número de cruzamentos é significativamente menor quando comparados com o controle, fato esse que pode ser explicado pelo aumento da área aversiva (clara), que possivelmente, diminuiu a exploração dos animais pelo fato dos mesmos terem preferência por uma área mais protegida (compartimento escuro). Tais dados permitem levantar a questão de se tal proporção seria mais adequada para o estudo do modelo de preferencia claro/escuro em peixes, considerando que o conflito posto entre a tendência a explorar ambientes novos e a esquiva de ambientes potencialmente aversivos poderia estar ampliado com o aumento da área clara.

Os dados de tempo gasto em cada compartimento (claro/escuro) obtidos com o aquário $75 \%$ escuro e $25 \%$ claro foram muito semelhantes aos dos controles, provavelmente porque uma maior área de segurança não interferiu na preferência. Porém observou-se que a frequência de cruzamentos diminuiu significativamente, provavelmente pelo fato dos peixes terem uma área protegida muito maior para ser explorada. 
Já os resultados obtidos com o aquário com 12,5\% escuro e 87,5\%claro constituem dados interessantes acerca do modelo de preferencia claro/escuro. Como se pode observar, não há uma diferença significativa entre o tempo gasto nos compartimentos claro e escuro para os peixes que passaram por esse aquário, fato que pode ser interpretado como uma atenuação do conflito entre a tendência a explorar ambientes novos e a esquiva de ambientes potencialmente perigosos. Essa atenuação provavelmente está relacionada à grande diminuição do ambiente seguro (compartimento escuro) apresentada pelo aquário com a proporção 12,5\% escuro e $87,5 \%$ claro, o que levaria os animais a explorarem de forma semelhante tanto o compartimento claro, como o compartimento escuro.

O aumento na exploração do aparato também pode ser evidenciado por uma maior frequência de cruzamentos pelos peixes expostos ao aquário com 12,5\% escuro e 87,5\% claro, em comparação com os controles. Tal comparação, apesar de não se mostrar diferenças significativas, fornece indícios de que a aversividade do compartimento claro pode estar atenuada.

De forma geral, o que se pode concluir a partir desses dados é que, quando se restringe em demasia uma área segura, pode haver uma atenuação do conflito exploração x evitação, pois os animais são levados a explorar o ambiente até então aversivo, mesmo que isso possa oferecer algum perigo, devido à inacessibilidade a um ambiente seguro. Assim, se o conflito está atenuado, provavelmente, a aversividade ao ambiente claro também estará, diminuindo com isso os comportamentos associados a ansiedade e aumentando a exploração do aparato como um todo.

\subsection{Aquário com metade do comprimento}

Os dados obtidos com a exposição dos peixes ao aquário com a metade do tamanho foram semelhantes aos dos sujeitos controle. A preferência pelo compartimento escuro se manteve, porém a frequência de cruzamento mais do que dobrou, quando comparada à dos controles. Esses dados permitem uma interpretação contraditória com relação ao modelo de preferência claro/escuro, pois ao mesmo tempo em que a preferência pelo compartimento escuro permanece, indicando que o compartimento claro continua sendo aversivo mesmo com a diminuição do comprimento do aparato, a frequência de cruzamentos mais do que dobra, indicando que os peixes estão explorando mais o aparato, possivelmente devido à atenuação do componente aversivo presente no compartimento claro. 
Uma hipótese poderia estar relacionada ao fato de que os animais, quando expostos a um aparato de comprimento menor, exibem uma capacidade maior de avaliar o potencial aversivo do ambiente, já que o ambiente a ser explorado é menor, o que, consequentemente, amplia as possibilidades de avaliação de risco. Entretanto, se fazem necessários estudos mais detalhados que levem em consideração as diferenças comportamentais apresentadas nos diferentes tipos de aquário. Por hora, não se tem dados da literatura para explicar essa contradição.

Apesar dessa contradição, os dados encontrados a partir desse parâmetro permitem que se discuta alguns resultados obtidos em um trabalho clássico do estudo da caixa claro/escuro como modelo de ansiedade (Belzung et al., 1987). Neste trabalho, os autores investigaram os efeitos de alguns ansiolíticos benzodiazepínicos, assim como de agonistas benzodiazepínicos inversos (ansiogênicos) na exposição de camundongos à caixa claro/escuro. $\mathrm{O}$ aparato utilizado no estudo, se comparado ao Hascoet et al. (1998, 2000a,b), possuía, aproximadamente, a metade do comprimento, e se diferenciava por ser constituído de dois compartimentos de tamanhos iguais, um claro e outro escuro, com um pequeno compartimento de cor neutra, separando o compartimento claro do escuro (idêntico ao aquário utilizado como controle no presente estudo). A partir desse aparato, Belzung et al.(1987) concluíram que os benzodiazepínicos utilizados, aumentavam o tempo gasto no compartimento claro, assim como a frequência de cruzamentos, resultado interpretado por eles como uma resposta de atenuação dos comportamentos relacionados à ansiedade. Da mesma forma, os autores indicaram que os agonistas benzodiazepínicos inversos diminuíram o tempo gasto no compartimento claro, assim como o número de cruzamentos (efeito ansiogênico), concluindo de forma geral que tal modelo seria bom para os testes de drogas anticonflito.

Levando-se em consideração as semelhanças entre os dados obtidos no aquário com a metade do comprimento e os do trabalho de Belzung et al. (1987), pode-se levantar um ponto interessante acerca da importância de uma validação comportamental e paramétrica de qualquer modelo que se proponha a estudar emoções. Considerando que, com aparatos semelhante de dimensões praticamente iguais, manipulando medidas paramétricas obtivemos respostas muito parecidas com as obtidas com manipulações farmacológicas por Belzung et al. (1987), é inevitável questionarmos as variáveis que estão controlando a resposta de defesa no modelo da caixa claro/escuro. Assim, é evidente que a manipulação farmacológica altera padrões exploratórios na caixa claro/escuro, porém, não da para negar que, levando-se em 
consideração os resultados obtidos no aquário claro/escuro para peixes, é possível afirmar que as características do aparato poderiam ter uma influencia igual ou até maior sobre o comportamento do que no caso dos camundongos na caixa claro/escuro. É, portanto, difícil a determinação de qual(ais) variável(is) poderia(m) estar controlando os padrões comportamentais observados (drogas, características do aparato, ou ambas). Tal questão, talvez pudesse ser respondida com a manipulação de alguns parâmetros relacionados à composição da caixa claro/escuro para roedores, assim como foi proposto e discutido pelo presente trabalho. 


\section{Conclusão}

Utilizando-se dos dados discutidos até aqui, faz-se claro que a validação adequada de um modelo experimental para se investigar componentes emocionais (no caso, a ansiedade) subjacentes a respostas comportamentais relacionadas ao comportamento de defesa de qualquer animal, para além de uma validação farmacológica, necessita de uma validação comportamental e paramétrica que forneça dados que permitam um controle adequado das condições ambientais às quais os animais estão expostos. Da mesma forma é necessário o conhecimento da função de um determinado comportamento para o repertório daquela espécie, para que, a partir desse ponto, se possa interpretar com uma maior clareza e verossimilhança a que possível emoção se relaciona um determinado padrão comportamental.

Entretanto, o que se tem observado na literatura da área é uma maior preocupação com a validação farmacológica do modelo, relacionado a uma suposta validade de face, que se sustenta a partir de respostas a drogas semelhantes às obtidas na clínica, como é o caso dos benzodiazepínicos e a maioria dos modelos experimentais de ansiedade em roedores (Rodgers, 1997a, Rodgers et al., 1997b).

Da mesma forma, vários trabalhos que utilizam peixes como sujeitos e buscam investigar possíveis efeitos farmacológicos de substâncias como a nicotina, álcool, cocaína, ansiolíticos, antidepressivos, entre outros, sobre supostos modelos de emoção, como os trabalhos de Gerlai, Lee e Blaser (2006); Levin, Becan, e Cerutti (2007); Lopes-Patino, Cabral e Zhdanova (2008); Bencan, Sledge e Levin (2009); Gebauer, et al. (2011), muitas vezes não apresentam uma validação comportamental paramétrica adequada dos aparatos utilizados em seus estudos, inviabilizando um controle adequado sobre as variáveis que de fato controlam o comportamento observado e dificultando a interpretação da real função do comportamento (Blazer, Chadwick e McGinnis, 2010).

Tais dificuldades originárias de uma validação comportamental paramétrica inadequada acabam por produzir modelos um tanto quanto limitados que, quando replicados com pequenas variações, como por exemplo, o teste de uma outra droga com a mesma função farmacológica observada na clínica, produzem efeitos contraditórios, assim como os de alguns modelos de roedores discutidos por Rodgers et al. (1997a).

De forma alguma é pretensão deste trabalho questionar a validade e aplicabilidade de estudos de novos modelos para a compreensão das emoções utilizando uma abordagem 
farmacológica, até porque a mesma é de indispensável validade para que se possa testar a consistência de um modelo dessa natureza. O que se propõe com o presente trabalho é que se valorize mais a investigação do valor etológico dos comportamentos apresentados pelos animais nos aparatos aos quais são expostos, assim como o verdadeiro potencial aversivo presente nesses aparatos, para que, a partir dessas características controladas se possa ter uma maior clareza sobre as respostas ligadas ao comportamento de defesa da espécie, explorando de uma forma mais completa o potencial farmacológico do modelo. 


\section{Referências Bibliográficas}

ABOUHEIF, E.; AKAM, M.; DICKINSON, W. J.; HOLLAND, P.W.; MEYER, A.; PATEL, N. H.; RAFF, R. A.; ET AL. Homology and developmental genes. Trends in Genetics, v.13, n.11, p.432-433, 1997.

BELZUNG, C.; MISSLIN, R.; VOGEL, E.; DODD, R. H.; CHAPOUTHIER, G. Anxiogenic effects of methyl-[beta]-carboline-3-carboxylate in a light/dark choice situation. Pharmacology Biochemistry and Behavior, v. 28, n. 1, p. 29-33, 1987.

BENAROYA-MILSHTEIN, N.; HOLLANDER, N.; APTER, A.; ET AL. Environmental enrichment in mice decreases anxiety, attenuates stress responses and enhances natural killer cell activity. The European Journal of Neuroscience, v. 20, n. 5, p. 1341-1347, 2004.

BENCAN, Z.; SLEDGE, D.; LEVIN, E. D. Buspirone, chlordiazepoxide and diazepam effects in a zebrafish model of anxiety. Pharmacology, Biochemistry, and Behavior, v. 94, n. 1, p. 75-80, 2009.

BLANCHARD, D. C.; BLANCHARD, R. J. Ethoexperimental approaches to the biology of emotion. Annual Review of Psychology, v. 39, p. 43-68, 1988.

BLASER, R. E.; CHADWICK, L.; McGINNIS, G. C. Behavioral measures of anxiety in zebrafish (Danio rerio). Behavioural Brain Research, v. 208, n. 1, p. 56-62, 2010.

BOURIN, M.; HASCOËT, M. The mouse light/dark box test. European Journal of Pharmacology, v. 463, n. 1-3, p. 55-65, 2003 b.

BRANDÃO, M, L. As bases biológicas do comportamento: introdução à Neurociência. $4^{\mathrm{a}}$ ed. EPU, Brasil, 2004.

BROWN, G. E., SMITH, P. J. e PETERS, R. B. Effects of escapable versus inescapable shocks on avoidance behavior in the goldfish (Carassius auratus). Psychological reports, v.57, p 1027-1030, 1985.

CHAOULOFF, F.; DURAND, M.; MORMÈDE, P. Anxiety- and activity-related effects of diazepam and chlordiazepoxide in the rat light/dark and dark/light tests. Behavioural Brain Research, v. 85, n. 1, p. 27-35, 1997.

COSTALL, B.; JONES, B. J.; KELLY, M. E.; NAYLOR, R. J.; TOMKINS, D. M. Exploration of mice in a black and white test box: validation as a model of anxiety. Pharmacology, Biochemistry, and Behavior, v. 32, n. 3, p. 777-785, 1989.

CRAWLEY, J.; GOODWIN, F. K. Preliminary report of a simple animal behavior model for the anxiolytic effects of benzodiazepines. Pharmacology, Biochemistry, and Behavior, v. 13, n. 2, p. 167-170, 1980. 
CRAWLEY, J. N.; SKOLNICK, P.; PAUL, S. M. Absence of intrinsic antagonist actions of benzodiazepine antagonists on exploratory model of anxiety in the mouse. Neuropharmacology, v. 23, n. 5, p. 531-7, 1984.

CRAWLEY, J. N.; BELKNAP, J. K.; COLLINS, A.; CRABBE, J. C.; FRANKEL, W.; HENDERSON, N.; HITZEMAN, R. J.; MAXSON, S. C.; MINER, L. L.; SILVA, A. J.; WEHNER, J. M.; WYNSHAW-BORIS, A.; PAYLOR, R. Behavioural phenotypes of inbred mouse strains: implication and recommendations for molecular studies. Psychopharmacology, v. 132, p. 107-124, 1997.

FILE, S. E. Recent developments in anxiety, stress, and depression. Pharmacology, Biochemistry, and Behavior, v. 54, n. 1, p. 3-12, 1996.

GENN, R. F.; TUCCI, S. A.; THOMAS, A.; EDWARDS, J. E.; FILE, S. E. Age-associated sex differences in response to food deprivation in two animal tests of anxiety. Neuroscience and Biobehavioral Reviews, v. 27, n. 1-2, p. 155-161, 2003.

GEBAUER, D. L.; PAGNUSSAT, N.; PIATO, A. L.; SHAEFER, I. C.; BONAN, C. D.; LARA, D. R. Effects of anxiolytics in zebrafish: Similarities and differences between benzodiazepines, buspirone and ethanol. Pharmacology, Biochemistry, and Behavior, v. 99, n. 3, p. 480-486, 2011.

GERLAI, R.; LEE, V.; BLASSER, R. Effects of acute and chronic ethanol exposure on the behavior of adult zebrafish (Danio rerio). Pharmacology, Biochemistry, and Behavior, v. 85, n. 4, p. 752-761, 2006.

GOUVEIA JR., A. Influências do Estado Hormonal no desempenho de ratos nos testes do labirinto em T elevado e nado forçado. Dissertação de Doutorado, Programa de PósGraduação em Neurociência e Comportamento. USP. São Paulo, 2001.

GOUVEIA JR., A., ZAMPIERI, R. A., RAMOS, L. A., SILVA, E. F., MATTIOLI, R., MORATO, S. Preference of Goldfish (Carassius auratus) for Dark Places. Revista de Etologia, v. 7, n. 2, p. 63-66, 2005.

GOUVEIA JR., A., MAXIMINO, C. e BRITO, T. M. Comportamento de peixes: Vantagens e utilidades nas neurociências. Faculdade de Ciências/UNESP. Bauru: SP, 2006.

GRAEFF, F. G. e BRANDÃO, M. L. Neurobiologia das Doenças Mentais. Lemos. São Paulo: SP, 1993.

GRAEFF, F. G. Neuroanatomy and neurotransmitter regulation of defensive behaviors and related emotions in mammals. Brazilian Journal of Medical and Biological Research = Revista Brasileira De Pesquisas Médicas E Biológicas / Sociedade Brasileira De Biofísica , v. 27, n. 4, p. 811-829, 1994.

GRAEFF, F. G. Serotonergic system. The Psychiatric Clinics of North America, v. 20, p. 4, 1997. 
GRAEFF, F. G. On serotonin and experimental anxiety. Psychopharmacology, v. 163, p. 3-4, 2002.

GRAY, J. A.; MCNAUGHTON, N. The Neuropsychology of Anxiety: An Enquiry into the Functions of the Septo-Hippocampal System. 2nd ed. Oxford University Press, USA, 2000.

HALL, D.; SUBOSKI, M. D. Visual and olfactory stimuli in learned release of alarm reactions by zebra danio fish (Brachydanio rerio). Neurobiology of Learning and Memory, v.63, p.40-229, 1995.

HAMDANI, EL-H.; STABELL, O. B.; ALEXANDER, G.; DOVING, K. B. Alarm reaction in the crucian carp is mediated by the medial bundle of the medial olfactory tract. Chemical Senses, v. 25, p. 103-109, 2000.

HASCOET, M.; BOURIN, M. A new approach to the light/dark test procedure in mice. Pharmacology Biochemistry and Behavior, v. 60, n. 3, p. 645-653, 1998.

HASCOET, M.; BOURIN, M.; COLOMBEL, M. C.; FIOCCO, A. J.; BAKER, G. B. Anxiolytic like effects of antidepressants after acute administration in a four-plate test in mice. Pharmacology Biochemistry and Behavior, v. 65, p. 339-344, 2000a.

HASCOET, M.; BOURIN, M.; NIC DHONNCHADHA, Á. The influence of buspirone and its metabolite 1-PP on the activity of paroxetine in the mouse light/dark paradigm and four plates test. Pharmacology Biochemistry and Behavior, v. 67, p. 45-53, 2000b.

HOLMES, A.; ILES, J. P.; MAYELL, S. J.; RODGERS, R. J. Prior test experience compromises the anxiolytic efficacy of chlordiazepoxide in the mouse light/dark exploration test. Behavioural Brain Research, v. 122, n. 2, p. 159-167, 2001.

IIGO, M.; TABATA, M. Circadian rhythms of locomotor activity in the goldfish Carassius auratus. Physiology e Behavior, v. 60, n. 3, p. 775-781, 1996.

INOUE, K.; ZORRILLA, E. P.; TABARIN, A.; ET AL. Reduction of anxiety after restricted feeding in the rat: implication for eating disorders. Biological Psychiatry, v. 55, n. 11, p. 1075-1081, 2004.

JOHNSTON, A. L.; FILE, S. E. Sex differences in animal tests of anxiety. Physiology e Behavior, v. 49, n. 2, p. 245-250, 1991.

KOMIYAMA, T.; KOBAYASHI, H.; TATENO, Y.; INOKO, H.; GOJOBORI, T.; IKEO, K. An evolutionary origin and selection process of goldfish. Gene, v. 430, n. 1-2, p. 5-11, 2009.

KLEEREKOPER, H.; TIMMS, A. M.; WESTLAKE, G. F.; ET AL. An analysis of locomotor behaviour of goldfish (Carassius auratus). Animal Behaviour, v. 18, n. 2, p. 317-330, 1970.

KOSTOWSKI, W.; PŁAŹNIK, A.; STEFAŃSKI, R. Intra-hippocampal buspirone in animal models of anxiety. European Journal of Pharmacology, v. 168, n. 3, p. 393-396, 1989. 
LEVIN, E. D.; BENCAN, Z.; CERUTTI, D. T. Anxiolytic effects of nicotine in zebrafish. Physiology \& Behavior, v. 90, n. 1, p. 54-58, 2007.

LÓPES-PATIÑO, M. A.; YU, L.; CABRAL, H.; ZHDANOVA, I. V. Anxiogenic effects of cocaine withdrawal in zebrafish. Physiology \& Behavior, v. 93, n. 1-2, p. 160-171, 2008.

MATTIOLI, R.; SANTANGELO, E. M.; COSTA, A. C.; VASCONCELOS, L. Substance P facilitates memory in goldfish in an appetitively motivated learning task. Behavioural Brain Research, v. 85, n. 1, p. 117-120, 1997.

MAXIMINO, C., BRITO, T. M., GOUVEIA JR., A. et al. A Comparative Analysis of the Preference for Dark Environments in Five Teleosts. International Journal of Comparative Psychology, v. 20, p. 351-367, 2007.

MAXIMINO, C.; BRITO, T. M.; COLMANETTI, R.; PONTES, A. A. A.; DE CASTRO, H. M.; DE LACERDA, R. I. T.; MORATO, S.; GOUVEIA, A. Parametric analyses of anxiety in zebrafish scototaxis. Behavioural Brain Research, v. 210, n. 1, p. 1-7, 2010 a.

MAXIMINO, C.; BRITO, T. M.; DA SILVA BATISTA, A. W.; ET AL. Measuring anxiety in zebrafish: A critical review. Behavioural Brain Research, v. 214, n. 2, p. 157-171, 2010 b.

MAXIMINO, C.; BRITO, T. M.; DIAS, C. A. G. D. M.; GOUVEIA, A.; MORATO, S. Scototaxis as anxiety-like behavior in fish. Nature Protocols, v. 5, n. 2, p. 209-216, 2010c.

MAXIMINO, C.; DA SILVA, A. W. B.; GOUVEIA JR, A.; HERCUlANO, A. M. Pharmacological analysis of zebrafish (Danio rerio) scototaxis. Progress in NeuroPsychopharmacology \& Biological Psychiatry, v. 35, n. 2, p. 624-631, 2011.

MCNAUGHTON, N.; CORR, P. J. A two-dimensional neuropsychology of defense: fear/anxiety and defensive distance. Neuroscience and Biobehavioral Reviews, v. 28, n. 3, p. 285-305, 2004.

MORATO, S.; BRANDÃO, M. L. Transporting rats to the test situation with a cart can modify rat exploratory behavior in the elevated plus maze. Psychobiology, v. 24, p.247-252, 1996.

MORATO, S.; BRANDÃO, M. L. Paradoxical increase of exploratory behavior in the elevated plus-maze by rats exposed to two kinds of aversive stimuli. Brazilian Journal of Medical and Biological Research $=$ Revista Brasileira De Pesquisas Médicas E Biológicas / Sociedade Brasileira De Biofísica, v. 30, n. 9, p. 1113-1120, 1997.

NEUMEYER, C., DÖR, S., FRITSCH, J. \& KARDELKY, C. Colour constancy in goldfish and man: influence of surround size and lightness. Perception, v. 31, p. 171-187, 2002.

NORTHCUTT, R. G. Localization of neurons afferentto the telencephalon in a primite bony fish, Polypteros palmas. Neuroscience Letters, v. 22, p. 219-222, 1981. 
OLSSON, I. A. S.; DAHLBORN, K. Improving housing conditions for laboratory mice: a review of "environmental enrichment". Laboratory Animals, v. 36, n. 3, p. 243-270, 2002.

PELLOW, S.; CHOPIN, P.; FILE, S. E.; BRILEY, M. Validation of open:closed arm entries in an elevated plus-maze as a measure of anxiety in the rat. Journal of Neuroscience Methods, v. 14, n. 3, p. 149-167, 1985.

PELLOW, S.; FILE, S. E. Anxiolytic and anxiogenic drug effects on exploratory activity in an elevated plus-maze: a novel test of anxiety in the rat. Pharmacology, Biochemistry, and Behavior, v. 24, n. 3, p. 525-529, 1986.

PORTAVELLA, M.; TORRES, B.; SALAS, C.; PAPINI, M. R. Lesions of the medial pallium, but not of the lateral pallium, disrupt spaced-trial avoidance learning in goldfish (Carassius auratus). Neuroscience Letters, v. 362, n. 2, p. 75-78, 2004.

PORTAVELLA, M.; VARGAS, J. P. Emotional and spatial learning in goldfish is dependent on different telencephalic pallial systems. The European Journal of Neuroscience, v. 21, n. 10, p. 2800-2806, 2005.

POUGH, F. H., Janis, C. M. e Heiser, J. B. A vida dos vertebrados. $3^{\text {a }}$ Ed. EDITORA Atheneu, BRASIL, 2003.

RODGERS, R. J.; CAO, B. J.; DALVI, A.; HOLMES, A. Animal models of anxiety: an ethological perspective. Brazilian Journal of Medical and Biological Research $=$ Revista Brasileira De Pesquisas Médicas E Biológicas / Sociedade Brasileira De Biofísica, v. 30, n. 3, p. 289-304, 1997a.

RODGERS, R. J. Animal models of "anxiety": where next? Behavioural Pharmacology, v. 8, n. 6-7, p. 477-496; discussion 497-504, 1997b.

RODRÍGUEZ, F.; DURÁN, E.; GÓMEZ, A.; OCAÑA, F. M.; ALVAREZ, E.; JIMÉNEZMOYA, F.; BROGLIO, C.; ET AL. Cognitive and emotional functions of the teleost fish cerebellum. Brain Research Bulletin, v. 66, n. 4-6, p. 365-370, 2005.

ROY, V.; BELZUNG, C.; DELARUE, C.; CHAPILLON, P. Environmental enrichment in $\mathrm{BALB} / \mathrm{c}$ mice: effects in classical tests of anxiety and exposure to a predatory odor. Physiology e Behavior, v. 74, n. 3, p. 313-320, 2001.

SALAS, C.; BROGLIO, C.; RODRÍGUEZ, F.; ET AL. Telencephalic ablation in goldfish impairs performance in a 'spatial constancy' problem but not in a cued one. Behavioural Brain Research, v. 79, n. 1-2, p. 193-200, 1996.

SANTANGELO, E. M.; MORATO, S.; MATTIOLI, R. Facilitatory effect of substance P on learning and memory in the inhibitory avoidance test for goldfish. Neuroscience Letters, v. 303 , n. 2, p. 137-139, 2001.

SCOBIE, S. R. e HERMAN, H. B. Detection, reaction, escape and debilitation thresholds for electric shock in Goldfish. Learning and motivation, v. 3, p. 442-456, 1972. 
SERRA, E.; MEDALHA, C.; MATTIOLI, R. Natural preference of zebrafish (Danio rerio) for a dark environment. Brazilian Journal of Medical and Biological Research, v. 32, n. 12, 1999.

SHIMADA, T.; MATSUMOTO, K.; OSANAI, M.; ET AL. The modified light/dark transition test in mice: evaluation of classic and putative anxiolytic and anxiogenic drugs. General Pharmacology, v. 26, n. 1, p. 205-210, 1995.

SPEEDIE, N.; GERLAI, R. Alarm substance induced behavioral responses in zebrafish (Danio rerio). Behavioral Brain Research, v. 188, p. 168-177, 2008.

SPIELER, R. E., NELSON, C. A., HUSTON, J. P. e MATTIOLI, R. Post-trial administration of H-1 histamine receptor blocker improves appetitive reversal learning and memory in goldfish, Carassius auratus. Neurosciences Letters, v. 277, n. 1, p. 5 - 8, 1999.

STRIEDTER, G. F. Brain homology and function: an uneasy alliance. Brain Research Bulletin, v. 57, n. 3-4, p. 239-242, 2002.

STRONGMAN, K. T. The effect of anxiety on food intake in the rat. Quarterly Journal of Experimental Psychology, v. 17, n. 3, p. 255, 1965.

TAKADA, M.; TACHIHARA, K.; KON, T.; YAMAMOTO, G.; IGUCHI, K.; MIYA, M.; NISHIDA, M. Biogeography and evolution of the Carassius auratus-complex in East Asia. BMC Evolutionary Biology, v. 10, n. 7, 2010.

THIEL, T. A.; WISENDEN, B. D. Field verification predator attraction to minnow alarm substance. Journal of Chemical Ecology, v. 28, n. 2, p. 243-447, 2002.

THORNDIKE, E. L. A note on the psychology of fishes. American Naturalist, XXXIII, 6 (consultado em http://psychclassics.yorku.ca/Thorndike/Animal/fish.htm\#f1) , ultimo acesso em 15/01/2010), 1911.

TREIT, D.; MENARD, J.; ROYAN, C. Anxiogenic stimuli in the elevated plus-maze. Pharmacology, Biochemistry, and Behavior, v. 44, n. 2, p. 463-469, 1993.

VARGAS, J. P.; LÓPEZ, J. C.; PORTAVELLA, M. What are the functions of fish brain pallium? Brain Research Bulletin, v. 79, n. 6, 2009.

WISENDEN, B. D. Olfactory assessment of predation risk in the aquatic environment. Philosophical Transactions of the Royal Society B: Biological Sciences, v. 355, p. 1205$1208,2000$.

YOSHIDA, M.; OKAMURA, I.; UEMATSU, K. Involvement of the cerebellum in classical fear conditioning in goldfish. Behavioural Brain Research, v. 153, n. 1, p. 143-148, 2004. 